\title{
A speech motor learning approach to treating apraxia of speech: Rationale and effects of intervention with an adult with acquired apraxia of speech
}

\author{
Anita van der Merwe \\ Department of Communication Pathology, University of Pretoria, South Africa
}

Background: In this paper the rationale for a treatment of apraxia of speech, the speech motor learning (SML) approach, is described and the effects of its application explored. The SML approach endeavours to address the underlying inability to plan and program the production of different speech motor targets (SMTs) in changing phonetic contexts and in utterances exceeding a single word/nonword in length. Aims: The aims of the study were to determine 1) if treatment effects generalized to untreated nonwords and untreated real words with trained vowels and consonants, 2) if a learning effect was maintained, 3) if the treatment task hierarchy of the SML approach could be confirmed, and 4) if the number of speech errors judged perceptually declined across the treatment period on treated and untreated stages. Methods \& Procedures: A multiple baseline single-subject design across behaviours and contexts was used to assess the effects of treatment with a speaker with chronic pure AOS. The first six stages of an eleven-stage treatment hierarchy were consecutively treated. The last five remained untreated.

Outcomes \& Results: During treatment, production of untrained nonwords and words containing trained and untrained SMTs improved. For three treated stages, the improvement was greater during the treatment phase than during baseline, for words, nonwords, or both. Stage 4 vowels only improved once treatment commenced. Untreated consonant clusters of Stage 10 improved negligibly. Improvement was 
maintained two years post-treatment. The number of speech errors decreased across the treatment period.

Conclusions: Preliminary evidence is provided supporting a general improvement in speech motor planning and programming ability for this participant. The relative value of components of the SML approach, need to be verified in future.

Key words: apraxia of speech, treatment, speech motor planning

Since the first report on the treatment of acquired apraxia of speech (AOS)

(Rosenbek, Lemme, Ahern, Harris, \& Wertz, 1973), there has been a growing interest in this field. Due to the demand for evidence-based clinical practice in SpeechLanguage Pathology a writing committee was appointed by the Academy of Neurologic Communication Disorders and Sciences (ANCDS) in 2001 to examine the current state-of-the-art and to develop evidence-based treatment guidelines for AOS (Wambaugh, Duffy, McNeil, Robin, \& Rogers, 2005; 2006). After scrutinizing the corpus of published treatment studies, the committee came to the conclusion that AOS treatment is still at the Phase-I or Phase-II levels of the five-phase model of clinical outcomes research (Robey \& Schultz, 1998).

Four general treatment approaches were identified. These were articulatorykinematic approaches, rate and/or rhythm treatments, alternative and augmentative communication treatments and intersystemic reorganization. Articulatory-kinematic treatment was the only approach that was "recommended" by the working committee of the ANCDS. Recommendation implies that benefits clearly exceed risks, but the evidence is less strong than in the case of a "strongly recommended" approach. The other three approaches were considered as treatment "options". 
Most articulatory-kinematic treatment investigations aimed to determine a treatment effect, and outcome measurements mainly focused on trained behaviours and not on functional gain for the client (Wambaugh et al., 2005). However, the problem appears to run deeper than the nature and scope of the studies that have been done. It seems that the nature of breakdown in speech production, the salient features of AOS of different degrees, and those behaviours that need to be targeted during treatment to achieve functional gain which has social validity, require further exploration. In a sense we are still at the stage of treatment development.

A treatment, the speech motor learning (SML) approach, (Van der Merwe, 1985) and its application are described in this paper. Level 3 evidence (Wertz, 2002), derived from the treatment of many clients from different language groups with childhood or acquired apraxia of speech and who were treated by many different clinicians, has been accumulated during the past thirty years. Research to verify aspects and also outcomes of the treatment has been undertaken. Some studies are unpublished and some have been published (Van der Merwe \& Tesner, 2000; Van der Merwe, 2007). These data demonstrated the potential value of this approach. The SML approach is imbedded in the theoretical framework for the characterization of pathological speech sensorimotor control (Van der Merwe, 2009; briefly named the four-level framework - FL framework), draws on evidence from motor control and speech motor control research, incorporates traditional articulatory-kinematic methods (Rosenbek et al., 1973; Wambaugh \& Nessler, 2004), utilizes motor learning principles (Schmidt \& Lee, 2005) and graphic stimuli (a form of inter-systemic reorganization), and includes a focus on speech prosody. According to Robey and Schultz (1998) the primary objectives of Phase 1 clinical outcomes research are to develop critical research hypotheses for later testing, to establish the safety of the new 
treatment and to detect the activity of a treatment. The aims of the present paper are (1) to explain and justify the theoretical rationale underlying the SML approach, (2) describe the methods of application, and (3) to explore the effects of this treatment on the speech of an adult with AOS. The focus of the current paper is on acquired apraxia of speech.

In the following section, conceptions of the underlying pathophysiology of apraxia of speech, its implications for treatment selection, and how it was addressed in published studies, will be reviewed. Next, based on the review, a speech motor learning approach and the assumptions on which it is based will be justified. Then the methods of the SML approach will be described and finally the single-subject study and its results will be described and discussed.

\section{THE UNDERLYING PATHOPHYSIOLOGY IN AOS CONSIDERED IN TREATMENT SELECTION}

Theory-driven treatment is an accepted principle in Speech-Language Pathology. Regarding the treatment of AOS, McNeil, Robin, and Schmidt (2009) suggest the most important variable is to target the probable pathophysiology underlying the disordered speech behaviours. Rosenbek and Jones (2009, p.271) consider the establishment of a hypothesized relationship among signs, functional components, and underlying pathophysiology, a principle for the treatment of sensorimotor speech disorders. However, they point out that for the experienced clinician it is relatively easy to relate the signs to the functional components, but “... confirming or even hypothesizing the underlying pathophysiology is fiendishly difficult". 
McNeil, et al. (2009, p 264) define AOS as "a phonetic-motoric disorder of speech production ... caused by inefficiencies in the translation of well-formed and filled phonological frames into previously learned kinematic information used for carrying out intended movements. These inefficiencies result in intra- and interarticulator temporal and spatial segmental and prosodic distortions" as surface signs. The speech errors are not due to deficits of muscle tone or reflexes, involuntary movements, disorders in the processing of response-produced feedback, or errors in linguistic-symbolic planning. Thus AOS is differentiable from the dysarthrias and from the speech level errors of speakers with aphasia and phonemic paraphasias. Following from this definition, treatment of AOS was traditionally conceptualized as articulatory-kinematic treatment of speech movement targets (SMTs) and attention to prosodic distortions.

Current articulatory-kinematic approaches aim to improve articulatory accuracy of SMTs in error. To elicit accurate articulation modelling, imitation, integral stimulation through visual and auditory modality cues, repeated practice, and gradual fading of clinician cues (Rosenbek, et al., 1973) are utilized. The bestresearched treatment is "sound production treatment". The emphasis is on minimal contrast practice of the sounds that the apraxic speaker produces incorrectly during pre-testing. The sounds are treated sequentially or simultaneously in word stimuli. (Wambaugh, Kalinyak-Fliszar, West, \& Doyle 1998; Wambaugh, Martinez, McNeil, \& Rogers, 1999). The rationale is that treatment "may act to improve access to or specification of the generalized motor program (GMP; Schmidt, 1975) and/or associated parameters of targeted sounds" (Wambaugh \& Nessler, 2004, p409).

Schema theory of motor control and learning (Schmidt, 1975; Schmidt \& Lee, 2005) has been used as theoretical basis for several treatment studies in AOS (Ballard, 
Maas, \& Robin, 2007; Hula, Robin, Maas, Ballard, \& Schmidt, 2008; Katz, McNeil, and Garst, 2010; Knock, Ballard, Robin, \& Schmidt, 2000). The schema theory proposes a centrally organized structure or program, the GMP. The GMP represents a sensorimotor memory pattern for a particular class of movements. Ballard, et al. (2007) and Maas et al. (2008) hypothesize how this theory can explain speech motor control. The suggestion is that a GMP may exist for, for example, plosives and another for fricatives, as these signify different "classes" of movements (Ballard et al., 2007). The schema theory was conceptualized to explain discrete body movements. The literal application to speech movements is debatable. According to Schmidt (2003) relative temporal invariance that is key to the GMP, was found not to hold for many kinds of actions. Speech may be such an action as coarticulation renders the movements for a specific sound in different words quite variable in time and space (Kent, 2004).

Within the context of schema theory, AOS may be a deficit in activating and/or selecting a GMP, may signify damage to the GMP itself, or may be an inability to correctly set the parameters specific to a situation (Knock et al., 2000; Maas et al., 2008). These authors target motor learning of sounds from different manner classes and apply motor learning principles. They choose to ground motor learning of speech in the schema theory because of its emphasis on motor learning (Knock et al., 2000, Hula et al., 2008; Ballard, et al., 2007). However, motor learning principles are compatible with both motor-program based theories and dynamic pattern theory of motor control (Magill, 2007). Application to treatment of apraxia of speech appears to be beneficial and seems justified irrespective of theoretical orientation.

Another school of researchers draws on the volitional-automatic dissociation in speech production. This orientation is consistent with Keller's (1987) postulation 
that speech motor memories can be retrieved from a store of frequently used syllables or the recalculation of infrequently used syllables. The dual-route explanation of AOS as presented by Whiteside and Varley (1998) proposes a direct route of encoding of frequently used words and syllables (i.e. automatic encoding) and an indirect route for the encoding of less familiar utterances (i.e. volitional encoding). The disorder in AOS is conceptualised as disrupted activation of stored schemata for high frequency words (in other words disrupted automatic encoding of familiar words). However, this theory does not explain the inability to produce novel words or the inability to produce a specific SMT correctly in isolation or in high-frequency and low-frequency words.

Aichert and Ziegler (2008) addressed the question of holistic syllable-sized motor programs in phonetic encoding in speakers with AOS. They tested the hypothesis of Levelt, Roelofs, and Meyer (1999) regarding a direct-access store or mental syllabary of motor patterns for frequently used syllables. Their conclusion was that the signs of apraxic speech cannot be explained as a problem of accessing the syllabary, but are rather indicative of damage to the syllable entries themselves (Aichert and Ziegler, 2008).

The hypotheses that the signs of AOS can be explained by a breakdown in automatic processing or direct route encoding of syllables or words need further exploration. However, collectively these works, which are grounded in a theory of volitional versus automatic access and control, offer important additional (other than the articulatory-kinematic approaches) guidelines for treating apraxia of speech. The implication is that the issue of novelty, processing demand, and automation of utterances, also need to be addressed during treatment. 
From this review of theory-driven treatments of apraxia of speech it appears that, irrespective of theoretical orientation, the primary objective of articulatorykinematic treatments as practiced by Wambaugh and colleagues $(1998 ; 2004)$, of the application of motor learning principles (Hula et al., 2008), of syllable learning (Aichert \& Ziegler, 2008), and of familiar word learning (Varley, Windsor \& Whiteside, 2005), is improvement of sound production accuracy. SMTs produced incorrectly at the start of treatment are usually targeted. Production of single units (words, syllables, or nonwords) or phrases (usually randomly chosen or of functional value) act as treatment tasks and thus SMTs in a particular coarticulation environment is taught.

The speech signs of AOS and the intricacies of speech motor control point to the need for a reconsideration of the theory underlying treatment approaches. The definition of McNeil et al. (2009) emphasises the disruption of temporal flow (movement across time) of speech. Fluency-disrupting behaviours such as articulatory groping and false starts all point to a disruption of flow, of consecutive recall of multiple SMTs, and of initiation of movements. Sound- and syllable segregation and slow speech rate (Wambaugh et al., 2005) further indicate a reduced range of planning which renders planning to sound-, syllable- or word-sized units. Errors increase with increased length of the utterance (Duffy, 2005). In other words the larger the planning load, the more errors occur. Unpredicted errors (Duffy, 2005; Van der Merwe, 2007) point to a loss of volitional control and internal predictive monitoring of output. The salient characteristics of AOS are often interpreted as "articulation" disorders. However, the signs of AOS implicate more than an articulation disorder of "static" articulatory placement, although this too is affected by spatial and temporal distortion. By inference treatment should, apart from the correct 
articulation of specific error SMTs, also address intersegment transitionalization, coarticulation, temporal flow of speech, consecutive recall of core motor plans and programs during planning of long utterances, repeated initiation during production of multiple SMTs, and automated production of learnt speech utterances (as opposed to highly controlled production; Van der Merwe, 2007).

In an attempt to address the underlying problems in AOS, the SML approach was developed (Van der Merwe, 1985). This approach is primarily grounded in the FL framework (Van der Merwe, 2009). This framework proposes a linguisticsymbolic phase that includes phonological planning during preparation of an utterance, followed by three motor phases. These are motor planning of speech, motor programming, and execution. The three phases are in accord with the motor control hierarchy for voluntary movements by higher, middle, and lower levels (Magill, 2007). Within this framework, AOS is primarily a disorder in speech motor planning, but programming may also be compromised. The assumption is that the SMT (speech sound) within the context of the utterance is the unit of planning. Speech motor planning implements core motor plans (CMPs) to drive motor goal selection for all speech structures involved in the production of a particular SMT. The CMP contains spatial specifications for actualizing place and manner of articulation, and temporal specifications. Planning is portrayed as generative and "plastic" to accommodate the influence of different phonetic contexts on the parameters of a CMP. These parameters are also adapted to speech rate, segmental duration, and interarticulatory synchronization requirements.

The inability to control speech motor planning would entail an inability to learn or recall invariant CMPs, identify the different motor goals in a plan by implementing an internal model (perhaps an inverse sensorimotor model - see later 
discussion), organize the concurrent and consecutive movements in each plan and for multiple CMPs, adapt the CMP to the phonetic context, control interarticulatory synchronization, centrally monitor through internal feedback the efference copy by comparing it to a internal model (perhaps a forward predictive model), keep adaptation of movements within the limits of equivalence, and to reach a critical acoustic configuration (Van der Merwe, 2009). Theory-driven treatment of apraxia of speech within the context of the FL framework necessitate that the components of motor planning be addressed.

\section{RATIONALE FOR THE METHODS OF THE SML APPROACH}

The FL framework provides guidelines on how a treatment approach for apraxia of speech should be structured. The overarching aim of the SML approach is to guide the individual with AOS to again control motor planning of speech and become as natural a speaker as possible. Motor programming and execution may also benefit. CMP recall of SMTs and realization through movement in utterances of increasing length and in systematically controlled phonetic contexts is central to the SML approach. The assumptions are that treatment should address the following:

\section{The ability to plan multiple movements for utterances in excess of one}

word/nonword: The normal adult speaker produces 3-5 syllables per second and the nervous system must simultaneously plan the movements of a large number of effectors to produce rapid sequences of vocal tract configurations (Smith, Goffman, Zelaznik, Ying, \& McGillem, 1995). For apraxic speakers, errors increase with increased length of the utterance (Duffy, 2005) not only because there is more opportunity to make mistakes, but also because of contextual loading and increased 
demands on a weak motor planning system. In SML treatment, series of nonwords simulate natural speech and production necessitates consecutive recall of different CMPs, anticipatory coarticulation of more than a single nonword, smooth intersegment transitions, and temporal flow of speech. Through rehearsal of series of nonwords the reduced range of planning and inability to do online planning during long utterances is addressed. To make this potentially possible, treatment starts with SMTs with the greatest ease of production (as experienced by each individual with AOS).

From a motor learning perspective, series of utterances as target may benefit speech motor learning. During production of series of nonwords the scope of attentional focus is extended and the speaker needs to 'manage attentional space'. Temporal flow of speech may be enhanced if the speaker with apraxia can manage attentional resources. Also, upcoming nonwords may shift the locus of attention. Research suggests that the learning of motor skills can be degraded by too much attention and an internal focus of attention (Freedman, Maas, Caligiuri, Wulf, \& Robin, 2007; Wulf \& Prinz, 2001).

The ability to recall CMPs, adapt the parameters of the CMP to systematically controlled and increasing amounts of variation in phonetic environment and changes in speech rate, and production of the adapted CMP within the critical acoustic configuration, i.e. without distortion: The aim is to facilitate relearning of (or reaccess to) CMPs and plasticity (the ability to adapt spatial and temporal specifications) of the CMP (Van der Merwe, 2009). During repeated production of sounds in controlled changing contexts, the opportunity exists to extract 'generalizable' or 'adaptive' rules (Jaric, Corcos, Agarwal, \& Gotlieb, 1993; Schmidt, 
1975) for planning. The changing phonetic contexts represent variable practice and diversification (Magill, 2007; Schmidt \& Lee, 2005; Wulf \& Schmidt, 1997) that may facilitate plasticity in the CMP. Also, conditions may foster implicit learning (Cleeremans, Destrebecqz, \& Boyer, 1998) of components of speech, for example, coarticulation that relies on implicit (versus procedural) knowledge.

The client is requested to judge production of each nonword for correctness (without groping, distortion, substitution, distorted substitution, addition or omission) and to self-correct if necessary. The emphasis is on the outcome and not on movement characteristics. Thus the auditory outcome becomes linked to production by drawing an inference. Auditory-kinesthetic links that may come to serve as internal models are constructed (Vihman, 2004). The challenge of motor learning is one of mastering and adapting sensorimotor transformations. Each transformation is bidirectional.

'Forward' indicates the causal direction - mapping motor commands onto the sensory consequences. 'Inverse' indicates the opposite direction - transforming a desired sensory consequence into the motor commands to achieve it. An inverse model is essential for most natural movements that depend on feedforward control (Kawato, 1999; Wolpert, Ghahramani, \& Flanaghan, 2001). During the production of the series of nonwords, the opportunity is created to learn or up-date an inverse model of each SMT in a variable environment.

After acquisition of a series of nonwords, the client is requested to increase the rate of production to reach normal rate. Rate changes also require adaptation of spatial and temporal parameters of CMPs (Van der Merwe, 2009). Speech rate appears to affect the entire command sequence and motor control strategy of an utterance (Smith et al., 1995). Slow rate that the individual with AOS adopt, implicate a control mode that is not habitual. It appears beneficial to attain normalized and habitual rate if and 
when possible. Rate increase while accuracy and uninterrupted speech flow is maintained probably signify more automatic production of utterances.

The ability to do internal predictive control: During motor learning the control mode is predominantly based on response-produced feedback control. Errors are corrected after they have been made. A more advanced control mode is central monitoring of the efference copy before production (Kawato \& Gomi, 1992; Van der Merwe, 2009). In SML treatment a delay-period of approximately three to four seconds is imposed after a nonword was produced consecutively correct (three to four times) during blocked practice and before a next trial. The individual is asked to wait a few seconds before the next trial and to prepare production of the same utterance during that delay. The aim is to facilitate retrieval from motor memory, do mental practice (covert rehearsal and action preparation), and strengthen predictive control of the internal forward model (Wolpert et al., 2001).

The ability to independently generate movements for speech production: Internally generated movement depends on an internal representation of the movement pattern. Studies of brain activation patterns show clear functional dissociation between internally mediated and externally guided or mediated movements (Lotze, Braun, Birbaumer, Anders, \& Cohen, 2003). Behavioural reactions to external stimuli are usually less impaired than internally initiated intentional behavioural actions (Romo \& Schultz, 1992). Imitation of a modelled word provides the opportunity for audiovisual to articulatory inversion and for a movement sequence to be prepared (Kent, 2005). Imitated speech production may be a first step to independent speech production. In SML treatment the nonwords are each first imitated and then the series, 
presented orthographically, are read independently. Reading the series of nonwords fosters self-initiated speech production.

The ability to produce speech automatically: Repeated practice facilitates learning, automation, and implicit knowledge. During repeated production, error frequency usually declines and production becomes more consistently correct (Magill, 2007; Schmidt \& Lee, 2005). Neural areas differ for new learning, overlearned automatic execution, and an attention condition during which pre-learned movements are to be monitored for outcomes. All these stages of learning should benefit neural plasticity and learning (Karni, 1996). In SML treatment, CMPs are rehearsed repeatedly in a growing corpus of sounds and in a growing number of phonetic contexts until the criterion of $80 \%$ correct articulation and uninterrupted speech flow (without startrestart behaviour) are achieved. SMTs and syllables therefore go through stages of new learning, automatic production, and redirected attention when introduced into a new set of SMTs and new phonetic contexts.

\section{METHODS OF THE SML APPROACH}

In the FL framework motor planning, programming, and execution are portrayed as being context sensitive (Van der Merwe, 2009) and influenced by factors such as initiation mode (imitated versus self-initiated), level of automaticity of an utterance, motor complexity, syllable structure, length, novelty, and rate of the utterance. These factors affect the complexity of sensorimotor control and are addressed in the methods of the SML approach. The stages of treatment, stimuli, and treatment steps follow the principle of progression from least complex to more complex. Treatment starts with the sounds with the greatest ease of production in 
CVCV nonwords (see justification of CVCV later). While treatment stimuli are initially less complex, the learning environment is complex from the start and involves high contextual interference (Magill, 2007; Schmidt \& Lee, 2005).

A random practice schedule, applied during the production of series of different nonwords, and variable practice of a CMP in different phonetic contexts signify high contextual interference. These conditions closely simulate natural speech and are present concurrently. Also, rate of production is gradually increased and movements are to become self-initiated. Nonword production may be novel and not as automatic as real word production. High contextual interference appears to enhance learning, transfer, and maintenance (Lin, et al., 2009; Magill, 2007). SML treatment endeavours to balance task difficulty to optimize learning. According to the challenge point framework, learning can only occur if the learner is challenged, but if the challenge is too great, learning may be hampered (Guadagnoli \& Lee, 2004).

\section{Stages in treatment}

Rating of the ease of production of the sounds of the language from the perspective of each individual client is the starting point of treatment. Three to four consonants (C) and three to five vowels $(\mathrm{V})$ with the greatest ease of production are selected as first target set and are simultaneously introduced when treatment commences. Rehearsal of the first target set constitutes Stage 1 in treatment. More difficult sounds are gradually incorporated into the corpus of targeted sounds. The $\mathrm{C}$ target set is expanded first and then the $\mathrm{V}$ set. The most difficult sounds ( $\mathrm{C}$ and $\mathrm{V})$ are added during the final stages of treatment. When new sounds are added, each addition denotes a new stage in treatment. 
During the initial stages, treatment stimuli comprise $\mathrm{CVCV}$ nonwords. CVC syllable structures and at a later stage CVCVC and CVCVCVC are gradually introduced across time. These introductions also denote next stages in the treatment hierarchy. The number of stages for each individual will depend on the severity of apraxia and the number of sounds that are added to the target set during a particular stage.

All the sounds (C, V, dipthongs, and clusters) of the language are rated on a continuum from one to four. The clinician produces the sound in isolation without the client getting any visual clues. The ability to recall the CMP and produce the sound independently is judged. The client imitates and then independently produces the sound in isolation at least four to five times. Both the clinician and the client do the ratings. One signifies mostly correct articulation (as judged by clinician) and greatest ease of production (as judged by client). Two signifies usually correct production and quite easy to produce. Three signifies usually incorrect production and quite difficult to produce. Four signifies consistently incorrect production and very difficult to produce. If ratings differ a sound is rated as, for example, a 1 to 2 sound. If the client is unable to partake in rating (e.g. due to aphasia), the clinician makes the judgment based on stimulability. The procedure should be repeated on three different days and test-retest results considered before the clinician decides on the first target set and plan the stages of treatment. Some measure of clinical judgment is called for.

\section{Treatment stimuli}

Series of nonwords are used as treatment stimuli. A series is, for example, mami, mamo, mamee. The nature and amount of phonetic variation between sounds in a nonword and across a series of nonwords is controlled and gradually increased. 
The CVCV treatment stimuli for each set of target sounds are varied according to five levels of phonetic variation. These are: Level 1 variation: $\mathrm{C} 1 \mathrm{~V} 1 \mathrm{C} 1 \mathrm{~V}+(+$ indicates variation of sounds in that position in a series): (e.g. baba, babe, babo, baboo, babi). Level 2: C1V1C2V+ (e.g. baka, bake, bako, bakoo, baki). Level 3: C1V1C+V1 (e.g. baka, bata, bafa). Level 4: C1V+C2V1 (e.g. beka, boka, booka, bika). Level 5: $\mathrm{C} 1 \mathrm{~V}+\mathrm{C}+\mathrm{V}+$ (e.g. beka, botoo, boofe, biko).

On the first two levels, the first three sounds remain constant in the series and motor complexity is hypothetically low. On Level 3 the first two sounds remain constant. On Level 4 only the first sound and the last two remain constant across a series. Consecutive changes in adaptation of the CMP of the first $\mathrm{C}$ to changing vowels will add to the motor complexity of this level. Complexity is further increased on Level 5 where only the first $\mathrm{C}$ remains constant in a series.

For the CVC syllable structure variation is as follows: of the vowel only, then of $\mathrm{C} 2$, and then of $\mathrm{C} 1$ in a series. Nonwords with a CVCVC structure can be constructed by adding a final $\mathrm{C}$ to the nonwords previously developed. As the number of target sounds increase, the possible permutations of combinations in both CVCV and CVC structures increase. Due to the programmatic nature of the stimuli a software program could be developed to generate the series of nonwords and to apply reduction of the permutations. Software can be downloaded from www.apraxiaanitavandermerwe.co.za. Each $\mathrm{C}$ is rehearsed in initial and medial position and in combination with other target sounds. The aim of treatment is not to practice each sound in every possible phonetic context. The premise is that systematic variable practice of each sound in different phonetic contexts would foster acquisition. A maximum of 40 series per variation level is adequate. 
Ordering of the levels of variation is theoretically and research based.

Reduplication of the same syllable appears in early words (Edwards \& Shriberg, 1983) and it might be because less variation between successive sounds may be easier to produce than more variation. Repetition of the same first syllable across nonwords in a series may also facilitate rhythmic production, and may therefore render those series (Levels 1 to 3 ) easier to produce than series with more variation. On the five levels of variation, variability between sounds in nonwords and across a series increase and therefore also the amount of contextual interference.

Nonwords are used for different reasons. Most important is the freedom to include and vary sounds as required. Nonwords are also free of semantic content (however, occasionally a nonword in a series may form a real word) and it is more than likely that the neural areas activated are motor areas without additional activation of language areas (Van der Merwe, 2009). Rehearsal could activate those areas that have lost the ability to plan and program speech movements. Nonwords simulate meaningful word production and show normal anticipatory and perseverative coarticulatory influences (Whalen, 1990). Nonwords are also not automated, and cannot be accessed directly from a sensorimotor store (Levelt, Roelofs, \& Meyer, 1999). Syllables in these nonwords may be familiar, as the nonwords have to abide to the phonotactic rules of the langauge. In the vocabulary of Levelt and co-workers (1999), the syllables could be recalled from a "mental syllabary". The interphonemic transitional gestural patterns for the syllables in the nonwords may in many instances be of high frequency use in the language (Kendall, McNeil, Shaiman, \& Pratt, 2005). However, the combination of syllables may be novel and may call for online planning Production may initially require attentional resources and foster acquisition of skills. 
All consonants and vowels are first targeted in nonwords with a $C V C V$ syllable structure. The "groundwork" for each consonant and vowel takes place in the CVCV context. In a study to determine the syllable shapes used by individuals with AOS, it was found that they use shorter words than normal speakers, a greater number of simple (open) syllable shapes, and significantly fewer CVC (closed) syllable shapes in spontaneous speech (Edmonds \& Marquardt, 2004). Speakers with AOS may pause between the $\mathrm{CV}$ and $\mathrm{C}$ during the production of $\mathrm{CVC}$ utterances or between the CVCV and C, in CVCVC utterances (Van der Merwe, Uys, Loots, \& Grimbeek, 1987). The CV syllable occurs in virtually all of the world's languages, in infant babbling, and in early words and has long been recognized as the preferred basic unit of speech articulation. Reduplicated babble (repeated syllable patterns) seen in infants provides experience in both prosody and sequences of articulation (Kent, 2004). Reduplication of this syllable (CVCV) is also most common in the first 50 words of children from different language groups. Children simplify speech production by reduplication of the CV syllable (Edwards \& Shriberg, 1983). CVCV nonwords also allow for phonetic interaction between adjacent syllables (Levelt, et al., 1999). For these reasons CVCV nonwords are initially implemented, followed by the CVC syllable and then longer structures that the individual with AOS may find harder to produce.

From the start of treatment real words should be identified from the nonword stimuli and rehearsed in phrases that contain only target sounds and the syllable structures already practiced. CV and VC words may also be used. Transfer to meaningful speech takes place after the particular nonword was rehearsed in a series. During each treatment session, practice of real words in phrases or sentences should be done to demonstrate the value of nonword practice and keep the client motivated. 
Initially real words are few, but as the target set expands more words can be identified.

Steps in treatment

The same steps are followed repeatedly during rehearsal of treatment stimuli. These take the client from imitated blocked practice of a nonword to self-initiated production of a series of nonwords. The steps are summarized in Appendix A to enhance ease of access. Important issues such as criteria for correct production and augmented feedback is addressed in that table.

\section{PURPOSE OF THE STUDY}

The current study signifies a first step to determine the outcomes of SML treatment of an individual with AOS. The purpose of the current study was to determine if (1) response generalization occurred to untreated exemplars of trained behaviours (nonwords), (2) stimulus generalization occurred to untreated real words with trained SMTs, (3) a learning effect was maintained on these exemplars and real words, (4) the treatment task hierarchy of the SML approach can be confirmed and experimental control exercised, (5) the number of speech errors judged perceptually declined across the treatment period on treated and untreated stages of the treatment task hierarchy. The latter potential effect of treatment, which may signify functional gain with social validity for the client, has not previously been studied.

\section{METHOD}

\section{Participant}


The participant was a university trained, bilingual, right-handed male who suffered an embolic cerebrovascular incident at the age of 52 years. He was a lecturer and business entrepreneur at the time of the stroke and continued with his business enterprises after the stroke. Self- and partner-report indicated no prior history of speech or language problems. During the first two months post-onset he did not communicate verbally, but used gestures and writing. He received articulation treatment that targeted SMTs in error. These were practiced in nonwords. His speech improved initially, but then reached a plateau according to the clinician and the client. This study started 30 months post-onset. At the time of the study he was 54-years-old. The research was explained to him and he gave informed consent to participate in the study.

The participant had normal hearing, no hemiplegia, no facial or tongue weakness, no involuntary movements or muscle tone disorders, and no dysarthria. Voice production was normal. There was no history of drooling or dysphagia. He did not display limb or oral apraxia, but responses for series of oral movements were delayed. At the time the current study commenced, his verbal output consisted of four- to five-word sentences or phrases, but he produced speech with great effort. Speech intelligibility was 23\%. The Boston Diagnostic Aphasia Examination (Goodglass \& Kaplan, 1983) (an informally translated Afrikaans version as the first language of the participant is Afrikaans) done at the time this study commenced, showed full score for all items except for fluency. Regarding pragmatic aspects of language (Prutting \& Kirchner, 1987) he responded appropriately except on prosody and fluency. Radiological reports (MRI and CT) revealed small lesions near Broca's area and the left parietal-occipital and right occipital areas of the brain. The radiologist suspected that he suffered a minor stroke/s before the major stroke that 
caused the speech problem. He displayed speech signs such as effortful trial-and-error articulation, dysprosody (slow speech rate and syllabic speech), prolonged vowels in multisyllabic words, inconsistent phoneme distortions, substitutions, distorted substitutions and voice onset time errors. These signs are typical of apraxia of speech (McNeil, et al., 2009) and the diagnosis of pure chronic AOS was made.

\section{Experimental stimuli}

Pre-treatment sound production assessment. The rating of ease of production of sounds was based on nine evaluations on three different days. The vowels, consonants, and word initial consonant clusters of the language were presented orthographically one at a time and the examiner produced each sound in isolation once without giving any visual clues. The participant could then produce the sound as many times as chosen (at least five times) to make a judgment of ease of production. A 4-point scale was used (see earlier explanation). The clinician judged stimulability and production accuracy of each sound on-line. Sounds were judged as easy when they were produced accurately on four of five trials ( $80 \%$ correct). The first evaluation was by consensus of the participant and researcher and then two ratings by the researcher and the participant independently took place. Taking these ratings and the stages of the treatment task hierarchy of the SML approach into consideration, 11 treatment stages were identified. These stages can be viewed in Table 1.

\section{Table 1 here}

Probe stimuli: Response generalization items. Response generalization probe stimuli consisted of 10 untreated nonwords for each treatment stage (i.e. 110 items). Stimuli were representative of the target sounds and syllable structures of each of the 11 stages. The stimuli were compiled according to certain criteria. On Stages 1 to 3 and 
Stage 5 each consonant had to occur at least twice in the initial position and most occurred at least once in the medial position. On Stage 4 the newly introduced vowels each had to occur at least three times. On Stages 6, 7, and 8 each consonant had to occur at least once in the initial and once in another position. On Stage 6 the new vowels (with one exception) were used. On Stages 9 to 11 each new consonant or consonant combination had to occur at least twice in the initial position. The initial position was regarded as important as it is considered a ("traditional") characteristic of speakers with AOS to make more errors on word initial sounds (McNeil et al., 2009). These rules were complied with as far as possible. The number of sounds available on each stage and the phonotactic rules of Afrikaans sometimes prohibited compliance with these rules. Nonwords also had to be kept meaningless (some sound combinations form real words).

Probe stimuli: Stimulus generalization items. Stimulus generalization refers to the occurrence of trained behaviours in untreated contexts (Ballard, 2001). Production of real words probably not only involves processing in cortical motor areas as nonwords do, but also in language-specific brain areas. On these grounds, real words may be considered to be a new context. Stimulus generalization probe stimuli consisted of 10 untreated real words for each treatment stage (i.e. 110 items). Items were representative of the target sounds and syllable structures of each of the 11 stages. Words were compiled according to the same criteria as the nonwords as far as possible. The number of times a specific sound occurred in the stimuli could however, not be controlled. Examples of the probe stimuli for the 11 stages are presented in Table 1. 
Treatment stimuli. Acquisition stimuli utilized during treatment comprised nonwords containing the speech sounds to be treated during each treatment stage and combined in the syllable structure to be treated. In total each of the 11 stages included a 100 series of nonwords (20 for each of the five variation levels). Each series contained seven nonwords. Treatment stimuli therefore consisted of 700 nonwords for each of the stages. Treatment stimuli were presented orthographically. For each stage 10 real words were identified and the participant had the opportunity at the completion of a stage to produce each twice, (i.e. twice during the 18-month treatment period). Words were not treated in this study as the limited number of sounds in early stages limited the available words that could serve as probe stimuli. A few words were included for motivational purposes. Exclusion of words is a deviation from the SML approach.

\section{Experimental design}

A multiple baseline single-subject design across behaviors and contexts was used. In this study the behaviours also signified successive levels to accommodate the successive stages in treatment. A successive level analysis strategy allows us to learn more about the relationship between successive steps or levels of a treatment program (Kearns, 1986). Correct production of untreated nonwords and words served as dependant variables. Learning was assessed by transfer tests (Magill, 2007).

Treatment was first applied to Stage 1 acquisition stimuli while all other stages remained untreated. When the criterion of $80 \%$ correct production of acquisition stimuli was reached during two consecutive treatment sessions, treatment of Stage 2 commenced. Once the criterion was reached for Stage 2, treatment of Stage 3 commenced (and so forth up to Stage 6). During Stages 1 to 4 new sounds were added to the target set of the previous stage. Stages 5 and 6 targeted previously acquired 
sounds in a new syllable structure (see Table 1). Stages 1 to 6 were treated consecutively while Stages 7 to 11 remained untreated. During treatment of Stage 6, the participant had to withdraw from treatment. His mother, who lived in a distant city, fell seriously ill. Being an only child he had to go and take care of her and later of her estate. He continued to live there.

Baseline phase. Three pre-treatment baseline probes (B1 to B3) were done before treatment of Stage 1 commenced. These were done on a Wednesday, Friday, and Monday of the following week. Baseline probes of not yet treated stages continued in order to assess response and stimulus generalization. Probe stimuli represented all stages of treatment. Extended baselines were therefore probed for all stages but Stage 1.

Probes. Apart from the three pre-treatment baseline probes, 21 probes were done during the 18 months treatment period. Five of the 21 were transition probes/tests (TT1 to TT5) before treatment of a next stage commenced. At least two probes were done during the treatment of a specific stage. These probes were administered at regular intervals of either two or three weeks. The time spent on treatment of a specific stage depended on the rate of progress of the participant. The number of sessions can be viewed on Figures 1 to 3 . Treatment was interrupted thrice due to a one to three week vacation period and in such instances more probes were done during the treatment period of a stage.

Probe procedures. Data were collected in the same way and in the same soundproof room each time. Responses were recorded on a Nachamichi versatile cassette system 
recorder. To control intensity levels and ensure clear recordings an assistant continuously monitored the VU meter. Each word or nonword was printed in font size 26 on a separate card. The examiner presented these cards to the participant one at a time without providing any model. He read the word or nonword from the card and therefore all productions were self-initiated. No time restriction was imposed and no feedback was given. The average time between response and presentation of a next stimulus was approximately 5s. Probes were done on a day during which no treatment was received.

Treatment phase. Treatment was conducted twice a week for an hour by the examiner. Treatment was always done in the same room in the department. The total number of treatment sessions was 89 across 18 months. Treatment of an upcoming stage was delayed until the criterion of $80 \%$ correct production of treatment stimuli of a specific stage was reached. Treatment stimuli were not scored continuously, but only when it became evident that the client was approaching the criterion level. During the last two treatment sessions of a specific stage, all productions were scored as error-free or not. The steps that were followed and the criteria applied are summarized in Appendix A.

Maintenance phase. Three maintenance probes (M1 to M3) were performed with intermediate periods of two and six weeks, two years after treatment was terminated. The reason for these periods was incidental. The rationale for doing these probes was to determine if scores remained in the same order than when treatment was terminated. During those two years the participant had the treatment material 
available and did initially revise this material on his own. He reported to have stopped practicing after the first six months.

Scoring and Reliability

Scoring number of nonwords and words produced correctly: A total of 5940 utterances were scored. The same rules were applied for all judgments. An utterance was judged as correct if it was free of any distortions, substitutions, omissions, additions, trans-positioning, and start-restart behavior. Syllable segregation and prolonged duration were accepted as the examiner regards these as compensatory strategies. No self-corrections were accepted. The first attempt was analyzed and scored as correct or incorrect. The data were scored from the audio recordings after termination of treatment. Two listeners, the examiner and a post-graduate research assistant, did the scoring independently. The assistant was not familiar with the design of the study. The researcher was aware of which audiotapes contained B1-B3 data, but the data of all other probes were analyzed blind. When all data were analyzed, the score sheets were compared. The number of error free responses on 10 stimuli was determined. A score for nonwords and for words for each stage was determined. The score for each stage (nonwords and words separately) was calculated as follows: If there were consensus between the two listeners, that particular score (number of words or nonwords judged as produced correctly, e.g. 6 out of 10) was accepted; if the scores of the two listeners differed with two marks (e.g. 6 and 8) the average of the two (7) was taken as score; if the score differed with only one mark, the highest of the two was taken; if the two scores differed with more than two marks, the items for that stage were analyzed again by a third listener (an experienced phonetician) and that 
mark accepted (this rarely happened). All three listeners were first-language Afrikaans speakers.

To determine reliability, a percentage of agreement between the two listeners was calculated. A point-to-point agreement for each item was determined. An interrater agreement of $89 \%$ was achieved.

The examiner and an experienced colleague judged the maintenance data independently. The same procedure as for probe data analysis was followed. Point-topoint inter-rater agreement was $98 \%$.

Analyzing and scoring frequency of types of speech errors: The examiner and an experienced phonetician (a first-language Afrikaans speaker) did narrow phonetic transcriptions and perceptual analysis of errors by consensus (Shriberg, Kwiatkowski \& Hoffmann, 1984). Judgments were made from the audio recordings. This made repeated re-play possible until consensus was reached. If consensus could not be reached a third listener was involved. The first attempt to produce a nonword or word was analyzed. The error categories were: (1) consonant substitutions, (2) voicing errors, (3) consonant distortions, (4) vowel errors, (5) omissions, additions, and transpositioning of speech sounds, and (6) start-restart behavior. Errors were scored as substitutions when replaced with another accurately produced sound. Voice onset time errors were noted as voicing errors. Distortion was defined as a sound not produced accurately due to either temporal distortion or to spatial misplacement of articulators. Vowel errors were noted as such, as it was almost impossible to determine perceptually if a vowel was distorted or substituted. Distorted substitutions were scored as two errors. Omissions, additions and trans-positioning were scored as such. Inter- and intra-syllabic schwa intrusions were considered as additions. Start- 
restart behavior included phenomena such as pauses filled with sound, audible tonic blocks and self-corrections. One such audible behavior was counted as one error. A single production could be scored as having multiple errors.

Perceptual analyses were performed on only a subset of the data due to the time-consuming nature of such analyses. Also, the purpose of this analysis was to determine if number of errors declined across time and it was assumed that analysis of a cross-sectional, representative sample of data would provide an overview of how speech was affected. Stages 3 and 5 that were treated and attained high scores eventually and also Stages 10 and 11 that were not treated and maintained low scores were chosen for perceptual analysis. The three pre-treatment baseline probes and the five transition probes of each of these stages were analyzed (i.e. 640 utterances).

To determine reliability of the perceptual analysis, re-transcription of $10 \%$ of the sample was done. These utterances were randomly chosen and were analyzed by consensus by the two listeners. Point-to-point agreement with the previous analysis was calculated at $83 \%$.

\section{RESULTS}

Number of nonwords and words produced correctly on treated and untreated stages

Figures 1 and 2 depict the data for treated Stages 1 to 6, and Figure 3 show the data for untreated Stages 7 to 11 . These data represent generalization to untreated nonwords and untreated real words. Treatment stimuli reached $80 \%$ acquisition when treatment on an upcoming stage commenced. In the description of results the term pre-treatment baseline (B1-B3) will refer to probes done on all stages prior to treatment of Stage 1 commenced. 
For each of the stages the number of error free responses on 10 stimuli was noted for nonwords and for words. Simple linear regression, using the least squares method, was performed to fit a regression line (trend line) (Kratochwill, 1978) to the scores in the baseline phase and the treatment phase. The quality of the regression model was tested using a one-tailed $F$-test at a $90 \%$ level of confidence. A one-tailed $t$-test was used to ascertain whether the slope regression parameter is significantly greater than zero at a $90 \%$ level of confidence. To ascertain whether the slope of the regression line, fitted to the treatment phase scores, is significantly greater than the slope of the regression line fitted to the baseline scores, the treatment phase data was transformed. This was done by deducting the predicted score, using the extrapolated baseline phase regression line, from each score in the treatment phase. A new regression analysis was performed on the transformed data. In those instances where the slope of the regression line fitted to the transferred data (hereafter referred to as the comparative slope - CS) is positive, improvement in scores was greater during the treatment phase than during the baseline phase. In some instances the quality of the regression was adversely affected by variability in the scores and a limited number of observations. The results are summarized in Table 2 .

\section{Table 2 here}

The general impression the data evokes is that experimental control was lost. Of the treated stages only Stage 4, during which three new vowels were introduced, showed no improvement before treatment commenced (CS 0.28 and 0.25 ). Stages 1 and 3 nonwords demonstrate a CS of 0.24 and 0.15 indicating a greater improvement during treatment than during baseline. Of the untreated stages, only Stage 10 (containing Stages 1 to 4 sounds in clusters) showed a negligible rise in scores (CS 0.02 for words and nonwords). 
On many stages where experimental control was lost, the rise in scores during baseline coincided with the introduction of treatment on some previous stage. Stage 2 scores improved during treatment of Stage 1 and Stage 3 scores during treatment of Stage 2. Stage 3 nonwords showed greater improvement (CS 0.15 ) once treatment of that stage commenced. Scores for Stages 5 (Stage 1 sounds in CVC structures) started to rise during treatment of Stage 1. Stage 6 nonword scores (Stage 2-4 sounds in CVC) started to increase once treatment on Stage 4 commenced.

Pre-treatment baseline (B1-B3) scores were not stable particularly for the early stages, but also did not show consistent improvement (with the exception of Stage 1 words). An improved score during the pre-treatment baseline was in most instances followed by a drop in score level during a next probe session. Generally the data portrays inconsistency in correct production. Variability appears to be less when nonwords and words contain sounds that the participant find very difficult to produce (see Stages 10 and 11). Difficult sounds are produced consistently incorrect. Scores on Stage 11 suggest that once improvement sets in, the same inconsistency as on earlier stages are evident.

The data appears to confirm the treatment hierarchy. Higher scores were attained for earlier stages than for later stages during pre-treatment B1-B3. Scores for nonwords ranged between one and four for Stages 1 to 6, and for Stages 7 to 11 between zero and one. For words, scores between one and six were achieved for Stages 1 to 7, while scores between zero and two were achieved for Stages 8 to 11 . Words generally showed higher scores than nonwords.

Maintenance data 
Three maintenance probes, done two years after treatment was terminated, showed retention of skills in nonword and word production. Scores were in the same ranges for all stages and where discrepancies existed between scores of nonwords and words, these were retained. Scores remained to be variable for all but Stage 10, that contained difficult clusters, and which still delivered scores between zero and one.

(Place Figures 1-3 here. If possible please place Figures 1 and 2 on two facing pages)

Speech error frequencies on treated and untreated stages

In Figure 4 the total number of errors judged perceptually is portrayed for two treated stages (3 and 5) and for two untreated stages (10 and 11). Data for the pre-treatment baseline probes B1 to B3 and for the five transition probes TT1 to TT5 are noted. The frequency of occurrence of error types across time is summarized in Table 3.

The slopes of the regression lines (see Figure 4) fitted to the total number of speech errors are negative (-5.40 to -2.61$)$, indicating a decrease in number of errors across time. All the slope parameters, except that of words of Stage 11, are statistically significantly negative $(\mathrm{p}<0,1)$. During $\mathrm{B} 1-\mathrm{B} 3$ the number of errors for Stage 3 were on average 25 for nonwords (i.e. 25 errors on 10 nonwords) and 28 for words (i.e. 28 errors on 10 words). During TT3-TT5, the number declined and varied between six and 10 for nonwords (average of eight errors) and two and nine for words (average of four errors). For Stage 5, the error frequency for B1-B3 varied between 20 and 45 for nonwords, and 15 and 27 for words. During TT3-TT5, error frequency also declined and varied between zero and 10 for nonwords, and two and four for words. More errors occurred on Stages 10 and 11 that are hypothetically higher in task 
complexity. However, the general trend was a decline in number of errors across time. B1-B3 averages for Stage 10 were 44 (nonwords) and 41 (words), while averages of transition probes declined and were 29 (nonwords) and 22 (words). Stage 11 averages were 49 (nonwords) and 35 (words) during B1-B3 and for transition probes these also declined and were 24 (nonwords) and 25 (words). There is no consistent trend regarding the difference between number of errors for nonwords and words for any of the stages. The tendency towards inconsistency in performance appears to prevail with regard to speech errors.

(Place Figure 4 and Table 3 here)

\section{DISCUSSION}

In this study the outcomes of the SML approach to treating AOS were investigated. The aims were to determine if speech motor planning skills will improve to the extent that generalization to untreated nonwords and words, of treated stages in the treatment hierarchy, would occur and be maintained. A further aim was to determine if the number of speech errors would decline across the treatment period on treated and untreated stages.

In summary, the results revealed that for this participant improved performance occurred on probe stimuli of some later stages in the treatment hierarchy before treatment on those stages commenced. The general impression is that experimental control was lost. Four stages did display some evidence of greater improvement once treatment commenced. Nonwords of Stages 1 and 3 showed a response to stage-specific treatment. Stage 4, during which three additional vowels were added to the target set, did not improve before treatment commenced. Scores of 
Stage 10 that was not treated remained consistently low. Improved performance was maintained once treatment was terminated. The number of errors judged perceptually decreased on lower (treated) and higher (untreated) stages across time. The absence of pre-treatment improvement on some stages (either nonwords, or both nonwords and words) speaks against a complete loss of experimental control and emphasizes the need for alternative explanations.

Response and stimulus generalization to treated and untreated stages in the treatment hierarchy

On treated and untreated stages the results reveal response generalization to untreated nonwords and sounds, and stimulus generalization to real words and production of target SMTs in word positions not treated. In some instances generalization coincided with the onset of treatment of a stage or a particular earlier stage. Pre-treatment baselines (B1-B3) of most stages (except Stage 1 words and Stage 5 nonwords) did not show consistent improvement before treatment commenced. This speaks against improvement that is totally unrelated to the treatment that was provided. However, treatment did evoke a general improved speech motor planning ability that influenced untreated SMTs and caused the loss of experimental control. At close inspection of the data it becomes evident that the production of words reacted to a greater extent to treatment of earlier stages. This issue will be addressed later. Improvement of nonword production was more closely linked to the introduction of treatment of a stage or of a particular earlier stage.

Researchers have proposed several reasons over the years to explain why transfer of learning (generalization) occurs (Magill, 2007). Two of the more prominent hypotheses are (1) the identical elements theory and (2) the transfer- 
appropriate processing theory. The first proposes that transfer is due to the degree of similarity between component parts, elements, or characteristics of two skills or performance contexts. The more similar the component parts, the greater the amount of positive transfer between them. Any observable part of a movement can be regarded as a component part or element (Thorndike 1914 in Magill, 2007). Specific SMTs such as lifting of the tongue or closure of the lips may perhaps be regarded as elements or component parts. Second, the transfer-appropriate processing theory proposes that transfer is due to the similarity in the cognitive processing characteristics required by two skills or two performance situations (Schmidt \& Lee, 2005). This view maintains that although similarity in skills can explain some transfer effects, it cannot explain all. A key point is the similarity between the cognitive processes required by the two performance situations. An example of transferappropriate processing is where application of specific rules is called for in both training and transfer tasks (Magill, 2007). According to Schmidt and Lee (2005) variable and random practice may strengthen transfer-appropriate processing.

The identical elements theory may explain the generalization that occurred to untreated sounds. A first possible reason for pre-treatment improvement may be that the phonetic features of the sounds of Stage 1 may have influenced the results. The $/ \mathrm{p} /, / \mathrm{m} /, / \mathrm{s} /$ and $/ \mathrm{x} /$ and seven vowels were introduced simultaneously. These consonants represent different manner classes (stop, nasal, and fricatives), different places of articulation (bilabial, alveolar, and velar) and also voiced $(/ \mathrm{m} /)$ and unvoiced sounds (/p/, /s/, /x/). Target vowels included rounded and unrounded, open and closed, and front to back vowels. The generalized improvement to untreated sounds may be due to experience gained in production of Stage 1 sounds that represent a range of phonetic features. Alveolar /s/ may have generalized to /1/ and /t/ of Stage 2, and /x/ to 
$/ \mathrm{k} /$. However, Stage 3 alveolar sounds $/ \mathrm{n} /$ and /d/ only started to improve when treatment of Stage 2 sounds $/ \mathrm{l} /, / \mathrm{t} /$, and $/ \mathrm{k} /$ commenced. The $/ \mathrm{p} /$ and $/ \mathrm{m} /$ of Stage 1 also did not generalize to Stage $3 / \mathrm{b} /$ before treatment of Stage 2 commenced. If phonetic features or identical elements are the operating variable, then, for example, alveolar /s/ of Stage 1 possibly could have prepared the participant to acquire /t/ of Stage 2 and /d/ of Stage 3, but the latter did not happen. It seems more likely that a hierarchy in motor complexity (as perceived by the participant) was determining onset of improvement of untreated sounds.

Improvement of treated and untreated sounds and therefore loss of experimental control may be a function of the methods of the SML approach and not due to some experimental flaw. Possibly transfer-appropriate processing (Schmidt \& Lee, 2005) and formation of rules (Magill, 2007) for motor planning can account for improvement in exemplars of trained tasks and untrained tasks of higher motor complexity. The SML approach "actively programme generalization” (Stokes \& Baer, 1977, p. 350). The great number of exemplars that are treated on each stage (100 series, each containing seven nonwords) and the way these are packaged may effect the formation of an induction (Stokes \& Baer, 1977) between a planned action and the required sensory outcome. During repeated production of a SMT in controlled changing contexts, the opportunity exists to extract 'generalizable' or 'adaptive' rules (Jaric, et al., 1993; Schmidt, 1975) for speech motor planning. In SML treatment the speaker gets repeated and structured opportunity to successively and in self-initiated mode recall and adapt CMPs of sounds to the systematically changing phonetic contexts. The ability to implement inverse models (Kawato, 1999; Wolpert, et al., 2001) and to translate SMTs into movements may have benefited. It is possible that transfer appropriate processing was facilitated. Random and variable practice of 
target sounds in various phonetic contexts may have benefited the participant's implicit ability to plan other SMTs of more difficult sounds. Also, repeated practice and automation of utterances of early stages, may have re-activated neural plasticity (Karni, 1996; Magill, 2007) which “paved the way” for more difficult speech skills.

But, as expected the ability to consistently implement forward models correctly remained compromised. Improved nonword and word production were not consistent. The variability in number of errors judged perceptually also demonstrates inconsistency in correct production. Inadvertent errors continued to occur. The selfcorrection data of this same participant taken from the same probes (Van der Merwe, 2007) also demonstrate this phenomenon.

The improved production of untreated sounds in this study speaks against the relearning of only certain manner and place of articulation groups. These results are therefore not congruent with the notion of a GMP for sound groups or classes (Ballard, et al., 2007; Knock, et al., 2000; Hula, et al., 2008) and generalization across classes. For example, no generalization occurred to more difficult vowels. It appears as if this participant gained experience in motor planning and could apply his improved ability to production of other untreated sounds, from different sound and manner groups, he found relatively easy to produce. In a previous report regarding generalization to production of words from the second language of this participant, it was found that second language speech production also improved even though the second language was not treated. English words were compiled exactly like the words in the current study and were probed simultaneously with the first language Afrikaans words (Van der Merwe \& Tenser, 2000).

For the early and more pronounced improvement of word production across stages some explanations can be offered. It is possible that probes acted as 
"treatment" for words and that the participant remembered and rehearsed these privately. An 18-month treatment period may have made this possible. However, improved production of words (relative to nonword production) of most stages occurred soon after onset of treatment at the time of the second probe session. Also, the probe stimuli contained a 110 words and it is unlikely that the participant could have remembered and privately rehearsed most of these so soon. A more viable explanation is that the production of real words is more automated and therefore more reactive to improved speech skills. Production of real words may pose less processing demands than nonwords (McNeill, Odell, \& Tseng, 1991). Word frequency may also influence the ability to produce words. This variable could not be controlled due to the constraints of available sounds, syllable structures, and requirements regarding frequency of occurrence of individual sounds in particular word positions. Chances are that some of the shorter words were high-frequency words, but it is unlikely for most words with CVCVC (Stage 7) and CVCVCVC (Stage 8) syllable structures. The conclusion seems to be that speech motor planning of real words responded soon after treatment commenced, but improved production was governed by ease of production of sounds and syllable structures of words. Real word production with difficult sounds on Stages 8 to 11 never reached scores higher than 7 out of 10 (inconsistently).

From a functional perspective the decrease in number of speech errors per word, is probably one of the most significant outcomes of the treatment. These were all untreated words. The implication is that his improved ability may also have generalized to many other words not probed. The decrease in speech errors judged perceptually could probably result in improved intelligibility of speech for communication purposes. 
Task hierarchy of the SML approach

A rise in scores of untreated stages was also induced by the fact that some stages were not completely unrelated. Stage 5 contained the sounds of Stage 1 in CVC syllable structures. Scores of Stage 5 started to rise very soon after treatment commenced. Stage 6 contained the sounds of Stages 2-4 in CVC structures. These nonword scores started to improve once the vowels of Stage 4 were treated. The SML approach first utilizes CVCV nonwords in treatment. In this study improved production of sounds in CVCV nonwords, generalized to production of the same sounds in CVC and CVCVC syllable structures. What we do not know is if treatment of CVC or CVCVC structures first would also induce generalization. In the SML approach the premise is that CVCV structures, which are found in early words of all or most languages, provide a foundation for speech motor learning. Reduplicated babble (repeated syllable patterns) seen in infants provides experience in both prosody and sequences of articulation (Kent, 2004). The current results appear to support the decision to initiate treatment with the CVCV syllable structure.

The SML treatment hierarchy is further determined by ease of production of speech sounds. Also, the sound target set is expanded by first adding consonants that the client finds easy to somewhat difficult to produce. Following this, vowels are added to the target set. The data support the notion of easier and more difficult sounds as addressed in different stages of treatment. Vowels that the participant experienced as difficult to produce, clearly only responded to direct treatment. The most difficult consonant clusters of Stage 10 were not treated and did not improve spontaneously. Consonant clusters are known to be high in motor complexity (Gierut, 2001; Rvachew \& Bernhardt, 2010). Vowels are usually not regarded as high in complexity. However two of the three vowels of Stage 4 were dipthongs. Vowels and particularly dipthongs 
require subtle changes in tongue, jaw, and lip movement with little tactile and proprioceptive feedback. Response-produced feedback is important for speech acquisition and the amount and nature of feedback during vowel production may inhibit spontaneous acquisition without direct intervention. This finding confirms the strategy of the SML approach to first expand the consonant target set, and then to expand the vowel repertoire.

In the SML approach easier SMTs are targeted first. The current data for this participant points to generalization of improved production of easier sounds to more difficult sounds. Whether generalization would have occurred in a reverse situation where difficult SMTs were introduced first cannot be predicted. From the child phonology field it has for a long time been suggested that generalization from more complex to less complex sounds may occur but not vice versa and that the preferred way to go is to first treat complex sounds (Powell \& Elbert, 1984). Evidence is forthcoming that the order of simple to more complex SMTs may be more beneficial for children with speech disorders. Rvachew and Bernhardt (2010) found that children who received treatment for simple targets made more progress toward the acquisition of target sounds and demonstrated emergence of complex untreated segments and feature contrasts. Children who received treatment for complex targets made little measurable gain. First targeting sounds with the greatest ease of production also resulted in positive outcomes in the current study.

The occurrence of perceptual errors on stimuli of Stages 3, 5, 10 and 11 also confirms the task hierarchy. The average number of perceptual errors during pretreatment baseline probes of Stages 3 and 5 was much lower than that of later stages.

\section{CONCLUSIONS}


The current investigation represents an attempt to provide data regarding the outcomes of SML treatment of an individual with pure AOS. Rehearsal of earlier stages induced generalization to more complex untreated SMTs and to other syllable structures. Experimental control was therefore lost. However, pre-treatment baselines did not show consistent improvement. This suggests that improved performance was not unrelated to treatment. A longer pre-treatment baseline may have rendered valuable information. Four stages did display evidence of greater improvement once treatment commenced.

Analysis of the data from the perspective of the identical elements theory, could not explain why generalization to some untreated SMTs occurred or did not occur. The transfer-appropriate processing theory suggests some reasons for the generalization to untreated sounds. The methods of the SML approach may have induced the formation of rules for translating SMTs into movements and adaptation of the CMP to different phonetic contexts during motor planning. A general improvement in speech motor planning was therefore effected. However, a hierarchy in motor complexity (from the perspective of the participant) also determined generalization from easier to more difficult SMTs.

The SML approach implements a successive level strategy (Kearns, 1986). The current study provided data regarding the relationship between successive stages of this treatment. Exactly which component or combination of components of the treatment induced the improved ability is not clear at this point. Research is currently underway to determine the relative value of first targeting easy versus difficult sounds, and blocked practice versus production of nonwords as a series. In future reaction time and movement time as parameters of improvement can also be 
researched in combination with errorless production. Of importance is to replicate the current study with other individuals. 


\section{REFERENCES}

Aichert, I., \& Ziegler, W. (2008). Learning a syllable from its parts: Cross-syllabic generalisation effects in patients with apraxia of speech. Aphasiology, 22(11), 1216-1229.

Ballard, K. J. (2001). Response generalization in apraxia of speech treatments: taking another look. Journal of Communication Disorders, 34, 3-20.

Ballard, K. J., Maas, E., \& Robin, D. A. (2007). Treating control of voicing in apraxia of speech with variable practice. Aphasiology, 21(12), 1195-1217.

Cleeremans, A., Destrebecqz, A., \& Boyer, M. (1998). Implicit learning: News from the front. Trends in Cognitive Sciences, 2(10), 406-416.

Duffy, J. R. (2005). Motor speech disorders: Substrates, differential diagnosis, and management ( $2^{\text {nd }}$ ed.). St. Louis: Elsevier Mosby.

Edmonds, L. A., \& Marquardt, T. P. (2004). Syllable use in apraxia of speech: Preliminary findings. Aphasiology, 18(12), 1121-1134.

Edwards, M. L., \& Shriberg, L. D. (1983). Phonology: Applications in communicative disorders. California: College-Hill Press Inc.

Freedman, S. E., Maas, E., Caligiuri, M. P., Wulf, G., \& Robin, D. A. (2007). Internal versus external: Oral-motor performance as a function of attentional focus. Journal of Speech, Language, and Hearing Research, 50, 131-136.

Gierut, J. A. (2001). Complexity in phonological treatment: Clinical factors. Language, Speech, and Hearing Services in Schools, 32, 229-241.

Gierut, J. A., Morrisette, M. L., \& Ziemer, S. M. (2010). Nonwords and generalization in children with phonological disorders. American Journal of Speech-Language Pathology, 19, 167-177.

Goodglas, H., \& Kaplan, E. (1983). The Assessment of Aphasia and Related 
Disorders. Philadelphia PA: Lea and Febiger.

Guadagnoli, M. A., \& Lee, T. D. (2004). Challenge point: A framework for conceptualizing the effects of various practice conditions in motor learning. Journal of Motor Behaviour, 36, 212-224.

Hula, S. N. A., Robin, D. A., Maas, E., Ballard, K. J., \& Schmidt, R. A. (2008). Effects of feedback frequency and timing on acquisition, retention, and transfer of speech skills in acquired apraxia of speech. Journal of Speech, Language, and Hearing Research, 51, 1088-1113.

Jaric, S., Corcos, D. M., Agarwal, G. C., \& Gottlieb, G. L. (1993). Principles for learning single-joint movements. II. Generalizing a learned behavior. Experimental Brain Research, 94, 514-521.

Karni, A. (1996). The acquisition of perceptual and motor skills: A memory system in the adult human cortex. Cognitive Brain Research, 5, 39-48.

Katz, W.F., McNeil, M.R., \& Garst, D.M. (2010). Treating apraxia of speech (AOS) with EMA-supplied visual augmented feedback. Aphasiology, 24 (6-8), 826837.

Kawato, M. (1999). Internal models for motor control and trajectory planning. Current Opinion in Neurobiology, 9, 718-727.

Kawato, M., \& Gomi, H. (1992). The cerebellum and VOR/OKR learning models. Trends in Neuroscience, 15, 445-453.

Kearns, K. P. (1986). Flexibility of single-subject experimental designs. Part II: Design selection and arrangement of experimental phases. Journal of Speech and Hearing Disorders, 51, 204-214.

Keller, E. (1987). The cortical representation of motor processes of speech. In E. 
Keller, \& M. Gopnik (Eds.), Motor and sensory processes of language. Hillside, NJ: Lawrence Erlbaum.

Kent, R. (2004). Normal aspects of articulation. In J. E. Bernthal, \& N. W. Bankson (Eds.), Articulation and phonological disorders, (pp. 1-62). Boston: Pearson.

Kent, R.D. (2005). Models of speech motor control: Implications from recent developments in neurophysiological and neurobehavioral science. In B. Maassen, R. D. Kent, H. F. M. Peters, P. H. H. M. van Lieshout, \& W. Hulstijn (Eds.), Speech motor control in normal and disordered speech. Oxford: Oxford University Press.

Kendall, D. L., McNeil, M. R., Shaiman, S., \& Pratt, S. (2005). Phonetic encoding of infrequent articulatory phonetic transitions. Aphasiology, 19(1), 39-52.

Knock, T. R., Ballard, K. J., Robin, D. A., \& Schmidt, R. A. (2000). Influence of order of stimulus presentation on speech motor learning: A principled approach to treatment for apraxia of speech. Aphasiology, 14(5/6), 653-668.

Kratochwill, T.R. (1978). Single Subject Research: Strategies for Evaluating Change. New York: Academic Press.

Levelt, W. J. M., Roelofs, A., Meyer, A. S. (1999). A theory of lexical access in speech production. Behavioral and Brain Sciences, 22(1), 1-75.

Lin, C., Fisher, B. E., Wu, A. D., Ko, Y., Lee, L., \& Winsteen, C. J. (2009). Neural correlate of the contextual interference effect in motor learning: A kinematic analysis. Journal of Motor Behavior, 41(3), 232-242.

Lotze, M., Braun, C., Birbaumer, N., Anders, S., \& Cohen, L. G. (2003). Motor learning by voluntary drive. Brain, 126(4), 866-872.

Maas, E., Robin, D. A., Hula, S. N. A., Wulf, G., Ballard, K. J., \& Schmidt, R. A. 
(2008). Principles of motor learning in treatment of motor speech disorders. American Journal of Speech-Language Pathology, 17, 277-298.

Magill, R. A. (2007). Motor learning and control: Concepts and applications. ( $8^{\text {th }}$ ed.). Boston: McGraw-Hill.

McNeil, M.R., Odell, K., \& Tseng, C. H. (1991). Toward the integration of resource allocation into a general theory of aphasia. Clinical Aphasiology, 20, 21-39.

McNeil, M. R., Robin, D. A., \& Schmidt, R. A. (2009). Apraxia of speech. In M. R. McNeil (Ed.), Clinical management of sensorimotor speech disorders $\left(2^{\text {nd }}\right.$ ed.). New York: Thieme.

Powell, T. W., \& Elbert, M. (1984). Generalization following the remediation of early- and late-developing consonant clusters. Journal of Speech and Hearing Disorders, 49, 211-218.

Prutting, C.A, \& Kirchner, D.M. (1987). Pragmatic aspects of language. Journal of Speech and Hearing Disorders, 52, 105-119.

Robey, R. R., \& Schultz, M. C. (1998). A model for conducting clinical-outcome research: An adaption of the standard protocol for use in aphasiology. Aphasiology, 12(9), 787-810.

Romo, R., \& Schultz, W. (1992). Role of primate basal ganglia and frontal cortex in the internal generation of movements. Experimental Brain Research, 91, 396407.

Rosenbek, J. C., \& Jones, H. N. (2009). Principles of treatment for sensorimotor speech disorders. In M. R. McNeil (Ed.), Clinical management of sensorimotor speech disorders ( $2^{\text {nd }}$ ed.). New York: Thieme.

Rosenbek, J. C., Lemme, M. L., Ahern, M. B., Harris, E. H., \& Wertz, R. T. (1973). A 
treatment for apraxia of speech in adults. Journal of Speech and Hearing Disorders, 38(4), 462-470.

Rvachew, S., \& Bernhardt, B. M. (2010). Clinical implications of dynamic systems theory for phonological development. American Journal of Speech-Language Pathology, 19, 34-50.

Schmidt, R. A. (1975). A schema theory of discrete motor skill learning. Psychological Review, 82, 225-260.

Schmidt, R. A. (2003). Motor schema theory after 27 years: Reflections and implications for new theory. Research Quarterly for Exercise and Sport, 74(4), 366-375.

Schmidt, R. A., \& Lee, T. D. (2005). Motor control and learning: A behavioral emphasis ( $4^{\text {th }}$ ed.). Champaign, IL: Human Kinetics.

Shriberg, L. D., Kwiatkowski, J., \& Hoffmann, K. (1984). A procedure for phonetic transcription by consensus. Journal of Speech and Hearing Research, 27, 456465.

Smith, A., Goffman, L., Zelaznik, H. N., Ying, G., \& McGillem, C. (1995). Spatiotemporal stability and patterning of speech movement sequences. Experimental Brain Research, 104, 493-501.

Stokes, T. F., \& Baer, D. M. (1977). An implicit technology of generalization. Journal of Applied Behavior Analysis, 10, 349-367.

Van der Merwe, A. (1985). Treatment program for developmental apraxia of speech and other speech disorders (title translated). Pretoria: $V \& R$.

Van der Merwe, A. (2007). Self-correction in apraxia of speech: The effect of treatment. Aphasiology, 21(6/7/8), 658-669.

Van der Merwe, A. (2009). A theoretical framework for the characterization of 
pathological speech sensorimotor control. In M.R. McNeil (Ed.), Clinical management of sensorimotor speech disorders $\left(2^{\text {nd }}\right.$ ed. $)$. New York: Thieme.

Van der Merwe, A. \& Tesner, H. (2000). Apraxia of speech in a bilingual speaker: Perceptual characteristics and generalization of non-language specific treatment. The South African Journal of Communication Disorders, 47, 79-89.

Van der Merwe, A., Uys, I. C., Loots, J. M., \& Grimbeek, R. J. (1987). The influence of certain contextual factors on the perceptual symptoms of apraxia of speech (title translated). South African Journal of Communication Disorders, 34,1022.

Varley, R., Windsor, F., \& Whiteside, S. (2005). Whole word therapy for acquired apraxia of speech. The Aphasiology Archive, University Library System, University of Pittsburgh.

Vihman, M. M. (2004). Early phonological development. In J. E. Bernthal \& N. W. Bankson (Eds.), Articulation and phonological disorders (pp 63-85). Boston: Pearson.

Wambaugh, J. L., Duffy, J. R., McNeil, M. R., Robin, D. A., \& Rogers, M. A. (2005). Treatment guidelines for acquired apraxia of speech: Synthesis and evaluation of the evidence. Journal of Medical Speech-Language Pathology, 14(2), xv xxxiii.

Wambaugh, J. L., Duffy, J. R., McNeil, M. R., Robin, D. A., \& Rogers, M. A. (2006). Treatment guidelines for acquired apraxia of speech: Treatment descriptions and recommendations. Journal of Medical Speech-Language Pathology, 14(2), xxxv-1xvii.

Wambaugh, J. L., Kalinyak-Fliszar, M. M., West, J. E., \& Doyle, P. J. (1998). Effects 
of treatment for sound errors in apraxia of speech and aphasia. Journal of Speech, Language, and Hearing Research, 41, 725-743.

Wambaugh, J. L., Martinez, A. L., McNeil, M. R., \& Rogers, M. (1999). Sound production treatment for apraxia of speech: Overgeneralization and maintenance effects. Aphasiology, 13(9-11), 821-837.

Wambaugh, J., \& Nessler, C. (2004). Modification of sound production treatment for apraxia of speech: Acquisition and generalisation effects. Aphasiology, 18(5/6/7), 407-427.

Wertz, R. T. (2002). Evidence-based practice guidelines: Not all evidence is created equal. Journal of Medical Speech-Language Pathology, 10(3), 11-15.

Whalen, D. H. (1990). Coarticulation is largely planned. Journal of Phonetics, 18, 335.

Whiteside, S. P., \& Varley, R.A. (1998). A reconceptualisation of apraxia of speech: A synthesis of evidence. Cortex, 34, 221-231.

Wolpert, D. M., Ghahramani, Z., \& Flanagan, J. R. (2001). Perspectives and problems in motor learning. Trends in Cognitive Sciences, 5(11), 487-494.

Wulf, G., \& Prinz, W. (2001). Directing attention to movement effects enhances learning: A review. Psychonomic Bulletin \& Review, 8(4), 648-660.

Wulf, G., \& Schmidt, R. A. (1997). Variability in practice and implicit motor learning. Journal of Experimental Psychology: Learning, Memory, and Cognition, 23, 987-1006. 
TABLE 1

Stages in treatment as determined by the ease of production of consonants and vowels and the hierarchy of syllable structures determined by the SML approach. New sounds that are introduced at each stage are underlined. Examples of probe stimuli per stage are also provided.

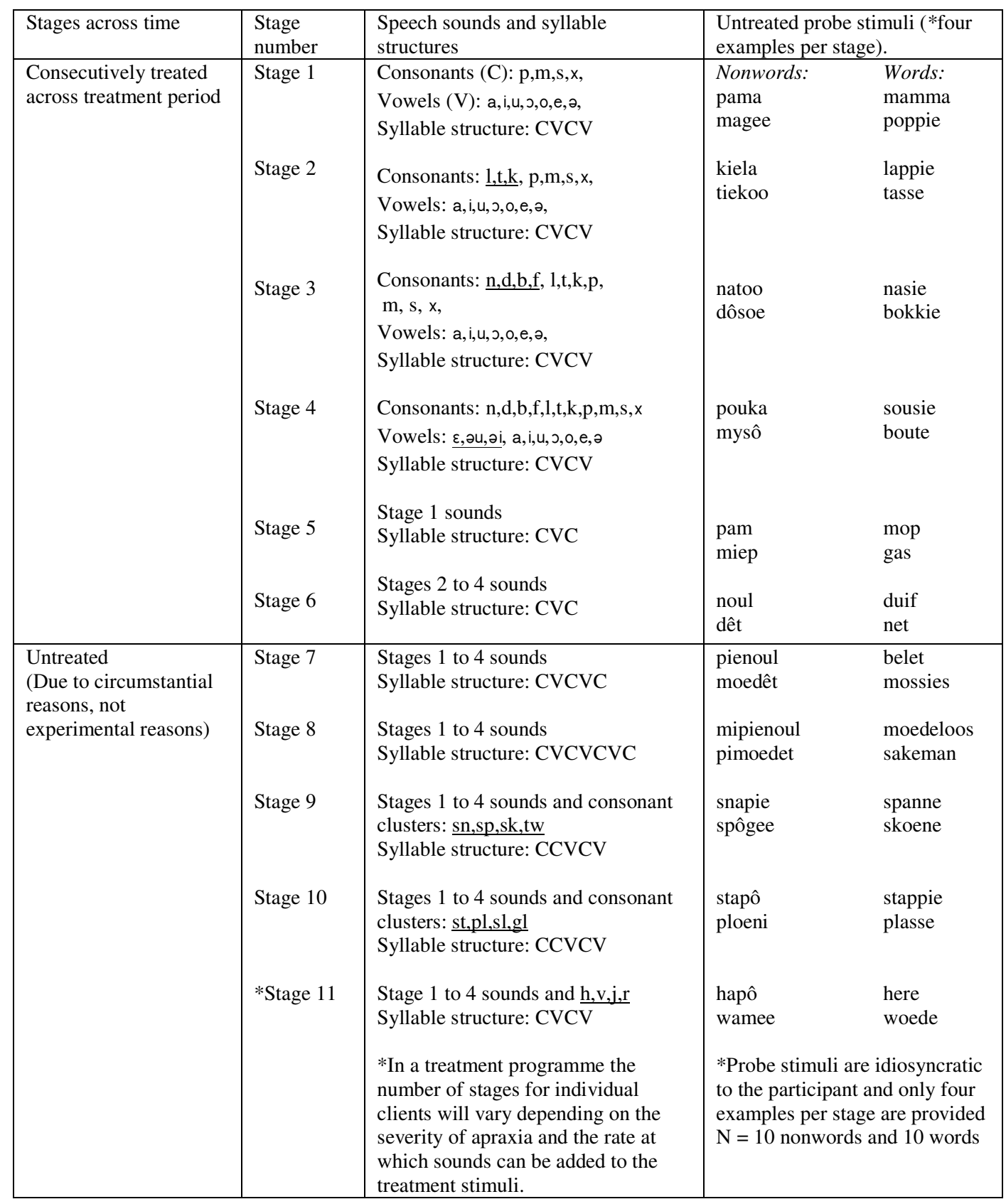


TABLE 2

Results of statistical analyses

\begin{tabular}{|c|c|c|c|c|c|c|c|c|}
\hline & & & \begin{tabular}{|l|} 
Number of Observations \\
\end{tabular} & \begin{tabular}{|l|} 
Mean Score \\
\end{tabular} & Mean $_{T}>$ Mean $_{B}(90 \%)$ & Slope & Quality of Regression & Slope Significantly $+(90 \%)$ \\
\hline \multirow[t]{3}{*}{ Stage 1} & Observed Data & \begin{tabular}{|l|} 
Baseline: \\
- Nonwords \\
- Words \\
\end{tabular} & $\begin{array}{l}3 \\
3\end{array}$ & $\begin{array}{l}3.67 \\
5.00\end{array}$ & $\begin{array}{l}\mathrm{N} / \mathrm{a} \\
\mathrm{N} / \mathrm{a}\end{array}$ & $\begin{array}{l}0.00 \\
1.00\end{array}$ & $\begin{array}{r}\text { Poor } \\
\text { Cannot Calculate }\end{array}$ & $\begin{array}{r}\text { No } \\
\text { Cannot Calculate }\end{array}$ \\
\hline & & $\begin{array}{l}\text { Treatment: } \\
\text { - Nonwords } \\
\text { - Words }\end{array}$ & $\begin{array}{l}21 \\
21\end{array}$ & $\begin{array}{l}7.38 \\
8.48\end{array}$ & $\begin{array}{l}\text { Yes } \\
\text { Yes }\end{array}$ & $\begin{array}{l}0.24 \\
0.14\end{array}$ & $\begin{array}{l}\text { Good } \\
\text { Good }\end{array}$ & $\begin{array}{l}\text { Yes } \\
\text { Yes }\end{array}$ \\
\hline & Transformed Data & \begin{tabular}{|l|} 
Treatment: \\
- Nonwords \\
- Words \\
\end{tabular} & $\begin{array}{l}21 \\
21 \\
\end{array}$ & $\begin{array}{l}\mathrm{N} / \mathrm{a} \\
\mathrm{N} / \mathrm{a} \\
\end{array}$ & $\begin{array}{l}\mathrm{N} / \mathrm{a} \\
\mathrm{N} / \mathrm{a}\end{array}$ & $\begin{array}{r}0.24 \\
-0.86 \\
\end{array}$ & $\begin{array}{l}\text { Good } \\
\text { Good }\end{array}$ & $\begin{array}{l}\text { Yes } \\
\text { No }\end{array}$ \\
\hline \multirow[t]{3}{*}{ Stage 2} & Observed Data & \begin{tabular}{|l|} 
Baseline: \\
- Nonwords \\
- Words \\
\end{tabular} & $\begin{array}{l}6 \\
6 \\
\end{array}$ & $\begin{array}{l}3.17 \\
4.67 \\
\end{array}$ & $\begin{array}{l}N / a \\
N / a\end{array}$ & $\begin{array}{l}0.60 \\
0.97\end{array}$ & $\begin{array}{l}\text { Poor } \\
\text { Good }\end{array}$ & $\begin{array}{l}\text { No } \\
\text { Yes }\end{array}$ \\
\hline & & $\begin{array}{l}\text { Treatment: } \\
\text { - Nonwords } \\
\text { - Words }\end{array}$ & $\begin{array}{l}18 \\
18\end{array}$ & $\begin{array}{l}8.11 \\
8.11\end{array}$ & $\begin{array}{l}\text { Yes } \\
\text { Yes }\end{array}$ & $\begin{array}{l}0.19 \\
0.03\end{array}$ & $\begin{array}{r}\text { Good } \\
\text { Poor }\end{array}$ & $\begin{array}{l}\text { Yes } \\
\text { No }\end{array}$ \\
\hline & Transformed Data & \begin{tabular}{|l|} 
Treatment: \\
- Nonwords \\
- Words \\
\end{tabular} & $\begin{array}{l}18 \\
18\end{array}$ & $\begin{array}{l}\mathrm{N} / \mathrm{a} \\
\mathrm{N} / \mathrm{a}\end{array}$ & $\begin{array}{l}\mathrm{N} / \mathrm{a} \\
\mathrm{N} / \mathrm{a}\end{array}$ & $\begin{array}{r}-0.41 \\
-0.94\end{array}$ & $\begin{array}{l}\text { Good } \\
\text { Good }\end{array}$ & $\begin{array}{l}\text { No } \\
\text { No }\end{array}$ \\
\hline \multirow[t]{3}{*}{ Stage 3} & Observed Data & \begin{tabular}{|l|} 
Baseline: \\
- Nonwords \\
- Words \\
\end{tabular} & $\begin{array}{l}9 \\
9 \\
\end{array}$ & $\begin{array}{l}1.56 \\
3.44 \\
\end{array}$ & $\begin{array}{l}N / a \\
N / a \\
\end{array}$ & $\begin{array}{l}0.17 \\
0.57 \\
\end{array}$ & $\begin{array}{l}\text { Poor } \\
\text { Good } \\
\end{array}$ & $\begin{array}{r}\text { No } \\
\text { Yes } \\
\end{array}$ \\
\hline & & \begin{tabular}{|l|} 
Treatment: \\
- Nonwords \\
- Words \\
\end{tabular} & $\begin{array}{l}15 \\
15 \\
\end{array}$ & $\begin{array}{l}5.27 \\
7.27 \\
\end{array}$ & $\begin{array}{l}\text { Yes } \\
\text { Yes }\end{array}$ & $\begin{array}{l}0.32 \\
0.33\end{array}$ & $\begin{array}{l}\text { Good } \\
\text { Good }\end{array}$ & $\begin{array}{l}\text { Yes } \\
\text { Yes }\end{array}$ \\
\hline & Transformed Data & \begin{tabular}{|l|} 
Treatment: \\
- Nonwords \\
- Words
\end{tabular} & $\begin{array}{l}15 \\
15\end{array}$ & $\begin{array}{l}\mathrm{N} / \mathrm{a} \\
\mathrm{N} / \mathrm{a}\end{array}$ & $\begin{array}{l}\mathrm{N} / \mathrm{a} \\
\mathrm{N} / \mathrm{a}\end{array}$ & $\begin{array}{r}0.15 \\
-0.24\end{array}$ & $\begin{array}{l}\text { Poor } \\
\text { Good }\end{array}$ & $\begin{array}{l}\text { No } \\
\text { No }\end{array}$ \\
\hline \multirow[t]{3}{*}{ Stage 4} & Observed Data & \begin{tabular}{|l|} 
Baseline: \\
- Nonwords \\
- Words \\
\end{tabular} & $\begin{array}{l}14 \\
14 \\
\end{array}$ & $\begin{array}{l}0.57 \\
3.50 \\
\end{array}$ & $\begin{array}{l}N / a \\
N / a\end{array}$ & $\begin{array}{r}-0.01 \\
0.02 \\
\end{array}$ & $\begin{array}{l}\text { Poor } \\
\text { Poor }\end{array}$ & $\begin{array}{l}\text { No } \\
\text { No }\end{array}$ \\
\hline & & \begin{tabular}{|l|} 
Treatment: \\
- Nonwords \\
- Words \\
\end{tabular} & $\begin{array}{l}10 \\
10 \\
\end{array}$ & $\begin{array}{l}4.80 \\
9.10 \\
\end{array}$ & $\begin{array}{l}\text { Yes } \\
\text { Yes }\end{array}$ & $\begin{array}{l}0.27 \\
0.26\end{array}$ & $\begin{array}{r}\text { Poor } \\
\text { Good } \\
\end{array}$ & $\begin{array}{l}\text { No } \\
\text { Yes }\end{array}$ \\
\hline & Transformed Data & $\begin{array}{l}\text { Treatment: } \\
\text { - Nonwords } \\
\text { - Words } \\
\end{array}$ & $\begin{array}{l}10 \\
10 \\
\end{array}$ & $\begin{array}{l}\mathrm{N} / \mathrm{a} \\
\mathrm{N} / \mathrm{a}\end{array}$ & $\begin{array}{l}\mathrm{N} / \mathrm{a} \\
\mathrm{N} / \mathrm{a}\end{array}$ & $\begin{array}{l}0.28 \\
0.25\end{array}$ & $\begin{array}{l}\text { Poor } \\
\text { Good }\end{array}$ & $\begin{array}{r}\text { No } \\
\text { Yes }\end{array}$ \\
\hline \multirow[t]{3}{*}{ Stage 5} & Observed Data & \begin{tabular}{|l|} 
Baseline: \\
- Nonwords \\
- Words \\
\end{tabular} & $\begin{array}{l}19 \\
19 \\
\end{array}$ & $\begin{array}{l}4.68 \\
6.63 \\
\end{array}$ & $\begin{array}{l}N / a \\
N / a \\
\end{array}$ & $\begin{array}{l}0.18 \\
0.25\end{array}$ & $\begin{array}{l}\text { Good } \\
\text { Good }\end{array}$ & $\begin{array}{l}\text { Yes } \\
\text { Yes }\end{array}$ \\
\hline & & \begin{tabular}{|l|} 
Treatment: \\
- Nonwords \\
- Words \\
\end{tabular} & $\begin{array}{l}5 \\
5 \\
\end{array}$ & $\begin{array}{l}8.40 \\
9.20 \\
\end{array}$ & $\begin{array}{l}\text { Yes } \\
\text { Yes }\end{array}$ & $\begin{array}{r}-0.50 \\
0.10 \\
\end{array}$ & $\begin{array}{l}\text { Poor } \\
\text { Poor }\end{array}$ & $\begin{array}{l}\text { No } \\
\text { No } \\
\end{array}$ \\
\hline & Transformed Data & \begin{tabular}{|l|} 
Treatment: \\
- Nonwords \\
- Words \\
\end{tabular} & $\begin{array}{l}5 \\
5 \\
\end{array}$ & $\begin{array}{l}\text { N/a } \\
\text { N/a }\end{array}$ & $\begin{array}{l}\mathrm{N} / \mathrm{a} \\
\mathrm{N} / \mathrm{a}\end{array}$ & $\begin{array}{l}-0.68 \\
-0.15\end{array}$ & $\begin{array}{l}\text { Poor } \\
\text { Poor }\end{array}$ & $\begin{array}{l}\text { No } \\
\text { No }\end{array}$ \\
\hline \multirow[t]{3}{*}{ Stage 6} & Observed Data & \begin{tabular}{|l|} 
Baseline: \\
- Nonwords \\
- Words \\
\end{tabular} & $\begin{array}{l}22 \\
22 \\
\end{array}$ & $\begin{array}{l}2.73 \\
6.59 \\
\end{array}$ & $\begin{array}{l}\mathrm{N} / \mathrm{a} \\
\mathrm{N} / \mathrm{a} \\
\end{array}$ & $\begin{array}{l}0.28 \\
0.38 \\
\end{array}$ & $\begin{array}{l}\text { Good } \\
\text { Good } \\
\end{array}$ & $\begin{array}{l}\text { Yes } \\
\text { Yes }\end{array}$ \\
\hline & & \begin{tabular}{|l|} 
Treatment: \\
- Nonwords \\
- Words \\
\end{tabular} & $\begin{array}{l}2 \\
2 \\
\end{array}$ & $\begin{array}{r}5.50 \\
10.00 \\
\end{array}$ & $\begin{array}{l}\text { Yes } \\
\text { Yes }\end{array}$ & $\begin{array}{c}-1.00 \\
- \\
\end{array}$ & $\begin{array}{l}\text { Cannot Calculate } \\
\text { Cannot Calculate }\end{array}$ & $\begin{array}{l}\text { Cannot Calculate } \\
\text { Cannot Calculate }\end{array}$ \\
\hline & Transformed Data & \begin{tabular}{|l|} 
Treatment: \\
- Nonwords \\
- Words \\
\end{tabular} & $\begin{array}{l}22 \\
22 \\
\end{array}$ & $\begin{array}{l}N / a \\
N / a \\
\end{array}$ & $\begin{array}{l}N / a \\
N / a \\
\end{array}$ & $\begin{array}{r}-1.28 \\
-0.38 \\
\end{array}$ & $\begin{array}{l}\text { Cannot Calculate } \\
\text { Cannot Calculate }\end{array}$ & $\begin{array}{l}\text { Cannot Calculate } \\
\text { Cannot Calculate }\end{array}$ \\
\hline \begin{tabular}{|l|} 
Stage 7 \\
\end{tabular} & Observed Data & \begin{tabular}{|l|} 
Baseline: \\
- Nonwords \\
- Words \\
\end{tabular} & $\begin{array}{l}24 \\
24 \\
\end{array}$ & $\begin{array}{l}2.38 \\
6.92 \\
\end{array}$ & $\begin{array}{l}\mathrm{N} / \mathrm{a} \\
\mathrm{N} / \mathrm{a}\end{array}$ & $\begin{array}{l}0.14 \\
0.28\end{array}$ & $\begin{array}{l}\text { Good } \\
\text { Good }\end{array}$ & $\begin{array}{l}\text { Yes } \\
\text { Yes }\end{array}$ \\
\hline Stage 8 & Observed Data & \begin{tabular}{|l|} 
Baseline: \\
- Nonwords \\
- Words \\
\end{tabular} & $\begin{array}{l}24 \\
24 \\
\end{array}$ & $\begin{array}{l}1.92 \\
3.33\end{array}$ & $\begin{array}{l}\mathrm{N} / \mathrm{a} \\
\mathrm{N} / \mathrm{a} \\
\end{array}$ & $\begin{array}{l}0.19 \\
0.20\end{array}$ & $\begin{array}{l}\text { Good } \\
\text { Good }\end{array}$ & $\begin{array}{l}\text { Yes } \\
\text { Yes }\end{array}$ \\
\hline \begin{tabular}{|l|} 
Stage 9 \\
\end{tabular} & Observed Data & \begin{tabular}{|l|} 
Baseline: \\
- Nonwords \\
- Words \\
\end{tabular} & $\begin{array}{l}24 \\
24\end{array}$ & $\begin{array}{l}0.96 \\
2.75\end{array}$ & $\begin{array}{l}N / a \\
N / a\end{array}$ & $\begin{array}{l}0.06 \\
0.21\end{array}$ & $\begin{array}{l}\text { Good } \\
\text { Good }\end{array}$ & $\begin{array}{l}\text { Yes } \\
\text { Yes }\end{array}$ \\
\hline Stage 10 & Observed Data & \begin{tabular}{|l|} 
Baseline: \\
- Nonwords \\
- Words \\
\end{tabular} & $\begin{array}{l}24 \\
24 \\
\end{array}$ & $\begin{array}{l}0.08 \\
0.38\end{array}$ & $\begin{array}{l}\text { N/a } \\
\text { N/a }\end{array}$ & $\begin{array}{l}0.02 \\
0.02\end{array}$ & $\begin{array}{l}\text { Good } \\
\text { Poor }\end{array}$ & $\begin{array}{l}\text { Yes } \\
\text { No } \\
\end{array}$ \\
\hline Stage 11 & Observed Data & \begin{tabular}{|l|} 
Baseline: \\
- Nonwords \\
- Words \\
\end{tabular} & $\begin{array}{l}24 \\
24\end{array}$ & $\begin{array}{l}0.88 \\
2.25\end{array}$ & $\begin{array}{l}\text { N/a } \\
\text { N/a }\end{array}$ & $\begin{array}{l}0.12 \\
0.12\end{array}$ & $\begin{array}{l}\text { Good } \\
\text { Good }\end{array}$ & $\begin{array}{l}\text { Yes } \\
\text { Yes }\end{array}$ \\
\hline
\end{tabular}




\section{TABLE 3}

Number of speech errors judged perceptually on nonwords and words on Stages 3, 5, 10, and 11 during the pre-treatment baseline probes (B1-B3) and the transition probes (TT1 - TT5). Speech error types: 1: Consonant substitutions, 2: Voicing errors, 3 : Consonant distortions, 4: Vowel errors, 5: Omissions, additions and transpositioning of speech sounds, 6: Start-restart behaviour

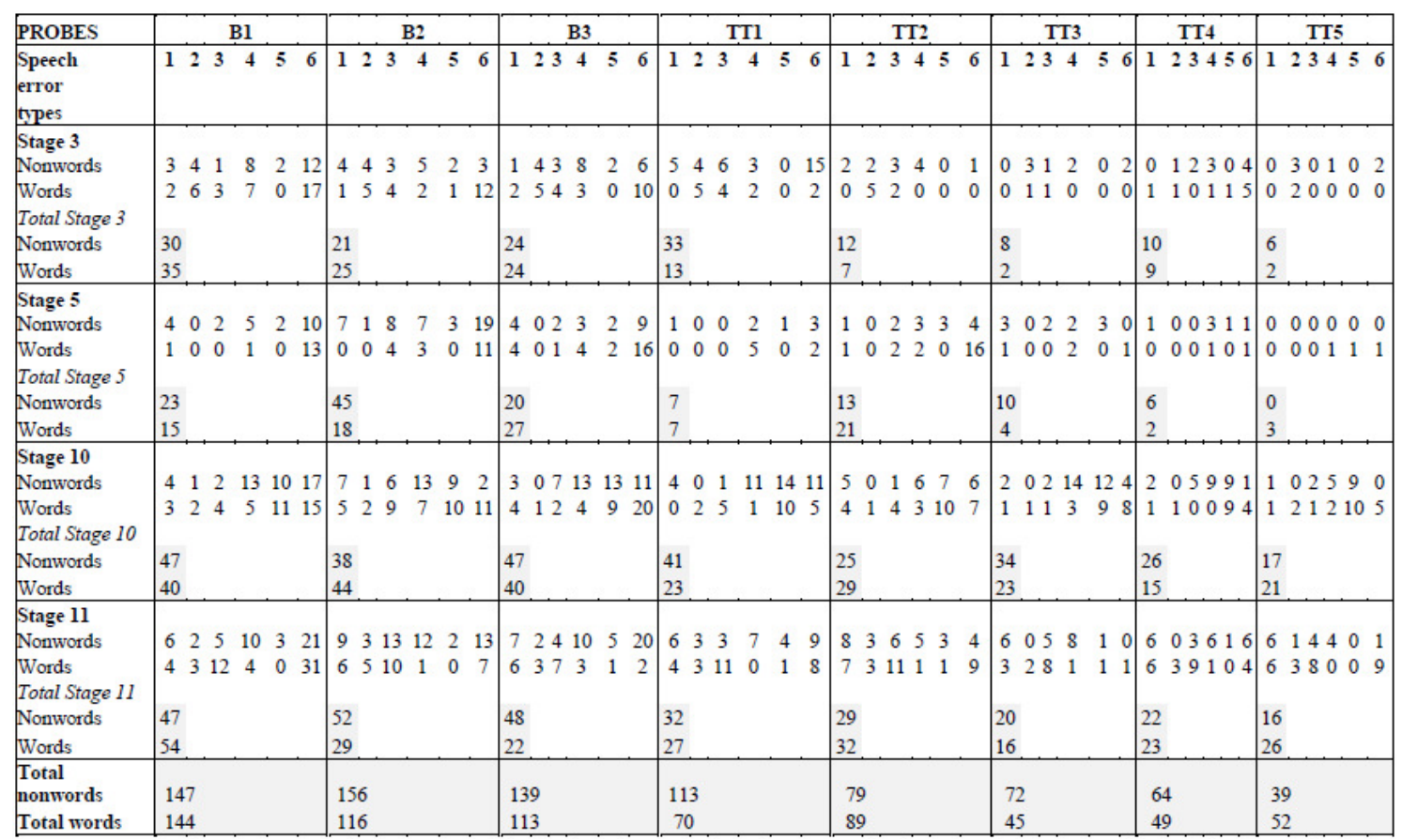



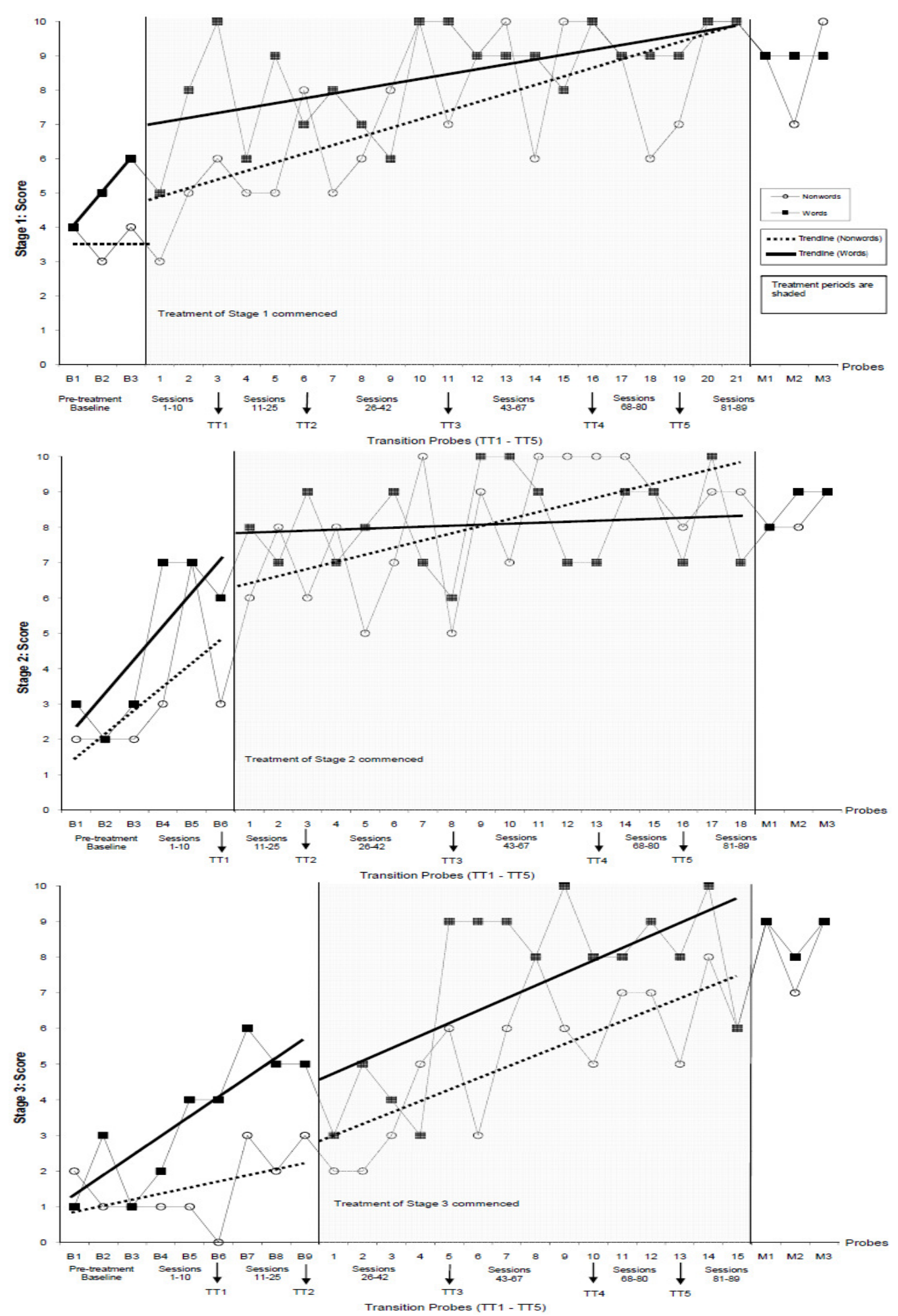

Figure 1. Stage 1 to Stage 3 scores during the pre-treatment baseline (B1-B3), the stage-specific baselines, and the subsequent probes. The five transition probes (TT1-TT5), indicating commencement of treatment of a following stage, are also indicated, together with the three maintenance probes (M1-M3). Stages 1 to 3 were treated. 

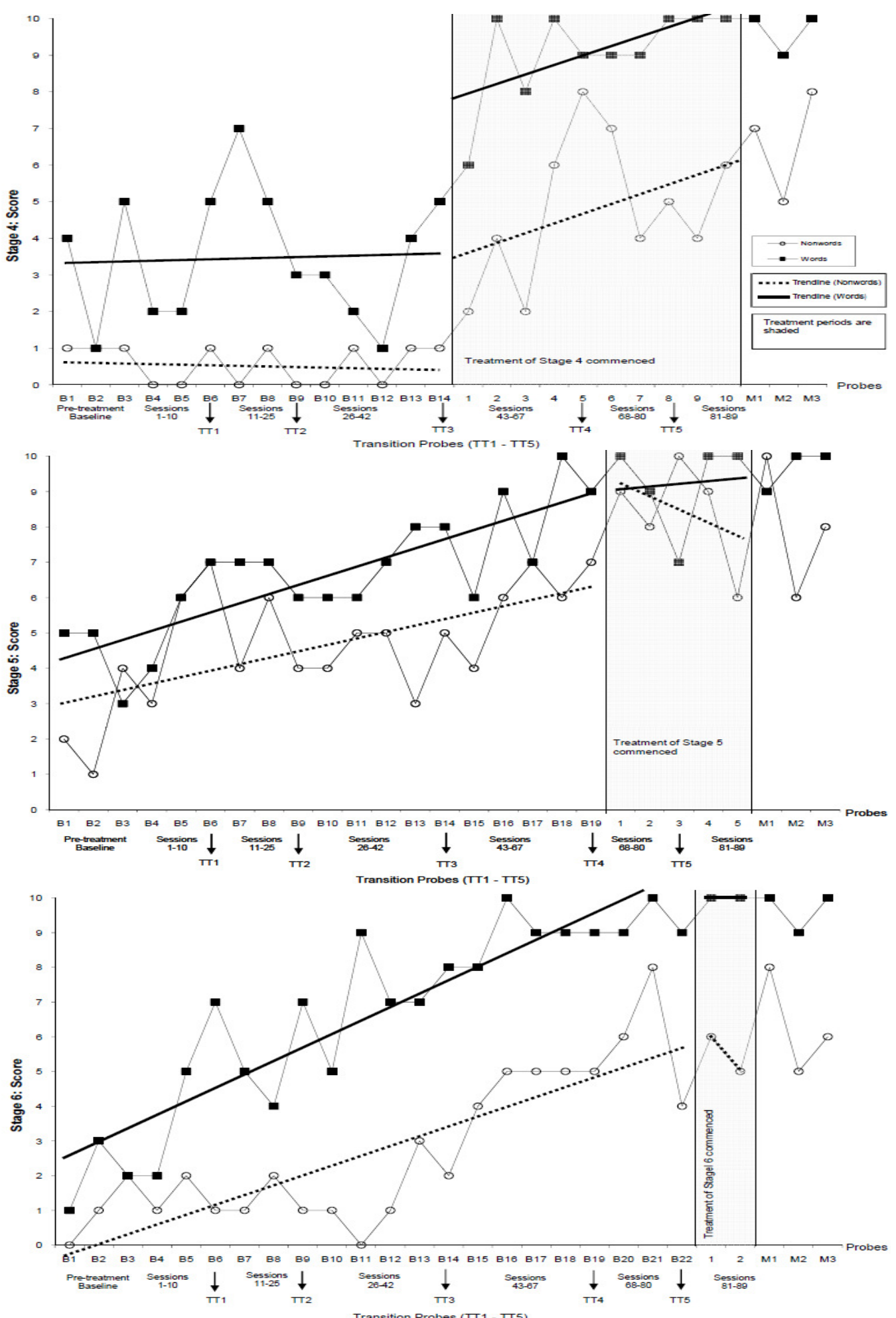

Figure 2. Stage 4 to Stage 6 scores during the pre-treatment baseline (B1-B3), the stage-specific baselines, and the subsequent probes. The five transition probes (TT1-TT5), indicating commencement of treatment of a following stage, are also indicated, together with the three maintenance probes (M1-M3). Stages 4 to 6 were treated. 

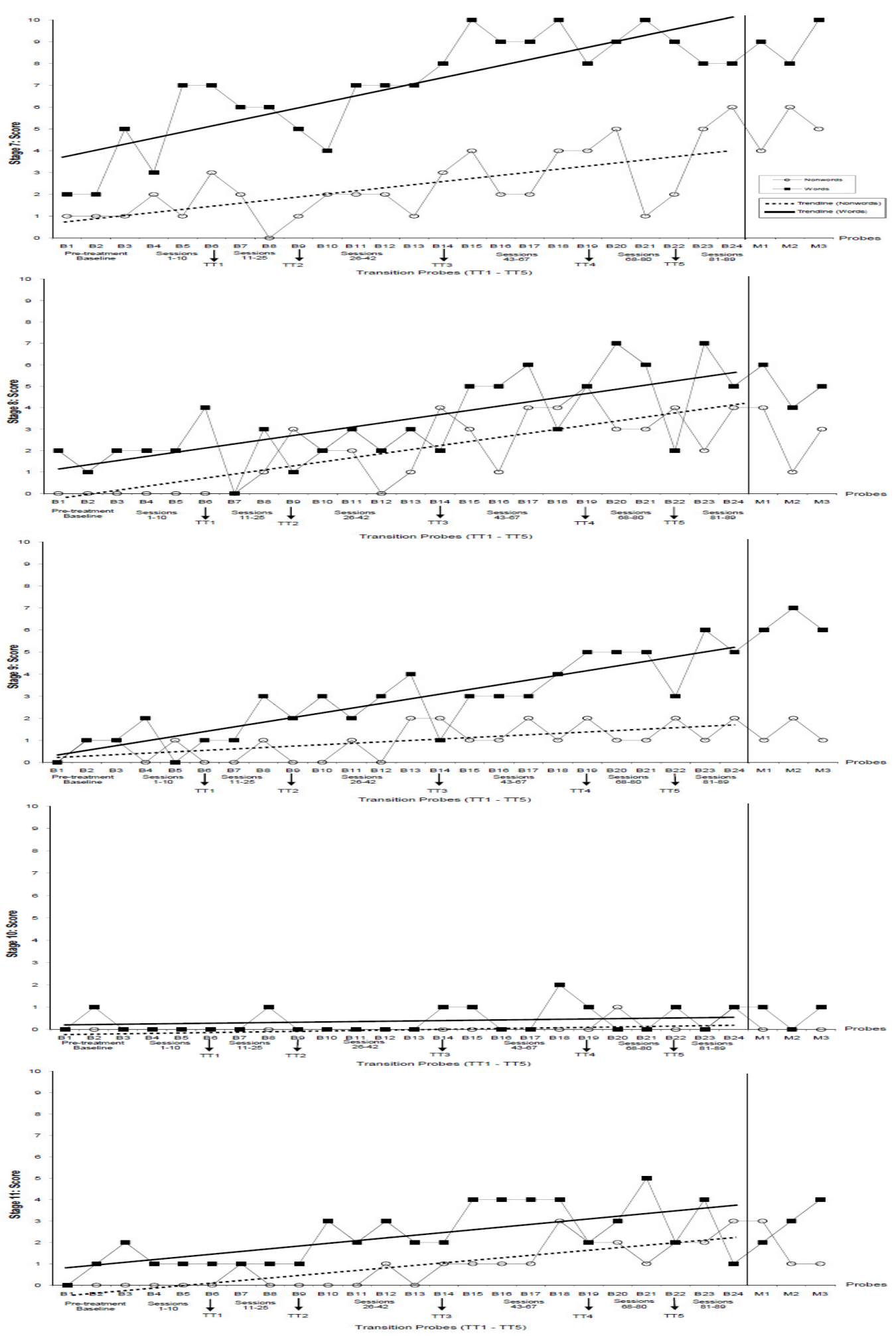

Figure 3. Stage 7 to Stage 11 scores during the pre-treatment baseline (B1-B3) and the subsequent baselines (B4-B24). The five transition probes (TT1-TT5), indicating commencement of treatment of a following stage, are also indicated, together with the three maintenance probes (M1-M3). Stages 7 to 11 were not treated. 

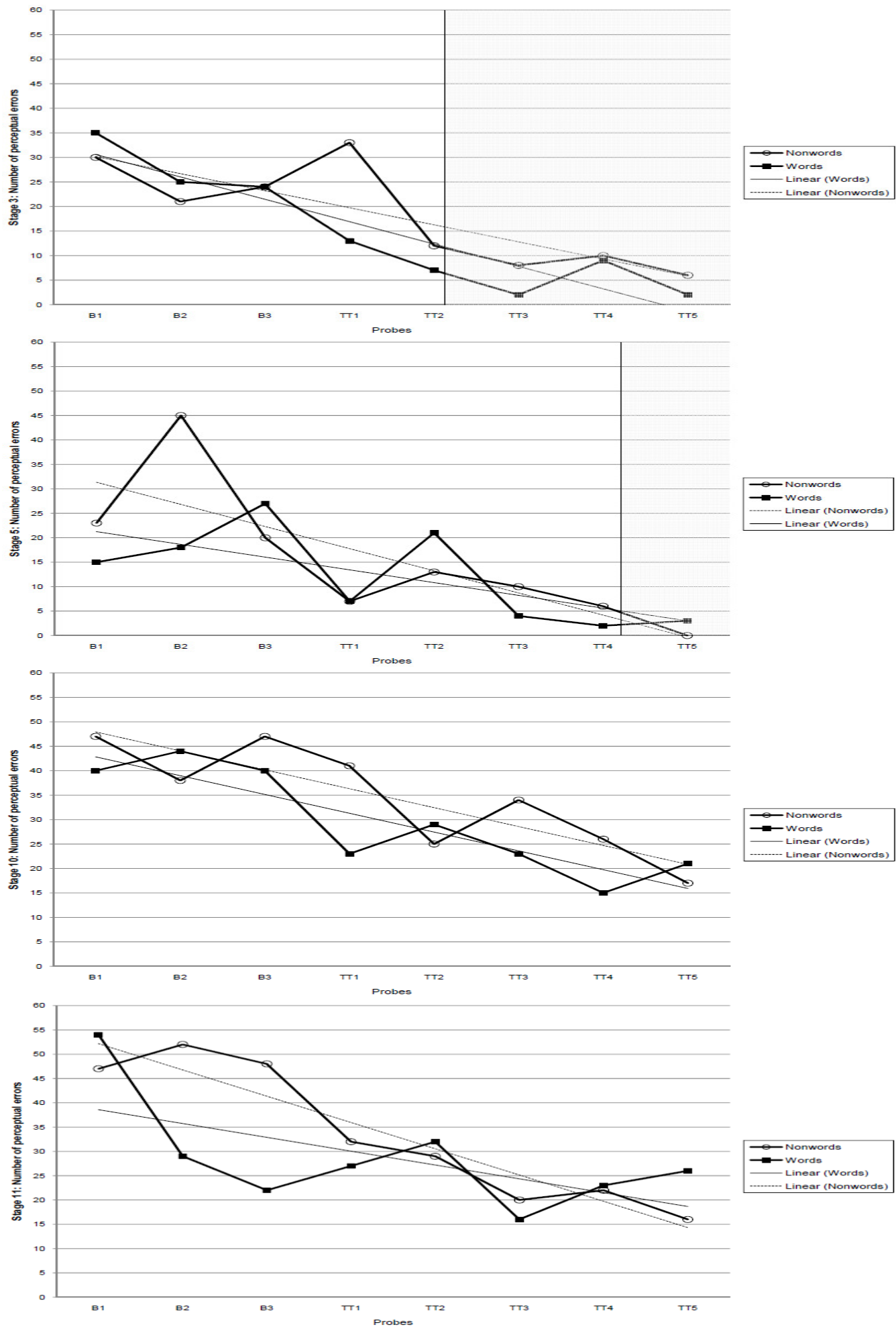

Figure 4. Number of speech errors judged perceptually during the pre-treatment baseline (B1-

B3) and during the transition probes (TT1-TT5) on Stages 3, 5, 10, and 11. 


\section{APPENDIX A \\ Summary of the steps followed during rehearsal of series of nonwords in SML treatment}

\begin{tabular}{|c|c|c|}
\hline Steps to be followed are similar & Steps continue: & General: \\
\hline $\begin{array}{l}\text { 1.Present the stimuli graphically to } \\
\text { the client, using the orthographic } \\
\text { symbols of the particular language } \\
\text { to represent a sound. Do blocked } \\
\text { practice of each nonword in a series } \\
\text { on imitation with integral } \\
\text { stimulation. First model the target } \\
\text { nonword three times while the } \\
\text { client looks and listens. Client } \\
\text { imitates nonword till criterion is } \\
\text { reached. } \\
\text { 2. Do self-initiated blocked practice } \\
\text { of each nonword. Clues from the } \\
\text { clinician can gradually fade till } \\
\text { production is self-initiated. Repeat } \\
\text { in self-initiated mode till } 80 \% \\
\text { criterion is reached. }\end{array}$ & $\begin{array}{l}\text { 3. Impose a pre-response delay- } \\
\text { period of } 3-4 \text { seconds once } \\
\text { criterion is reached. If production } \\
\text { is incorrect after delay do blocked } \\
\text { practice of nonword. Repeat } \\
\text { procedure till production is } \\
\text { correct after delay. } \\
\text { 4. Do consecutive production of } \\
\text { the nonwords in a series: first, on } \\
\text { imitation of each nonword } \\
\text { consecutively with integral } \\
\text { stimulation and then client reads } \\
\text { the series in self-initiated mode } \\
\text { till criterion is met. Model } \\
\text { production of a series } \\
\text { rhythmically - place stress on } \\
\text { syllables that vary. } \\
\text { 5. Increase rate of self-initiated } \\
\text { production of a series till criterion } \\
\text { is met. Client should try to } \\
\text { eliminate inter-syllabic breaks, } \\
\text { but if not possible accept this as a } \\
\text { natural means of compensation. } \\
\text { 6. Identify real words and phrases } \\
\text { containing these words and } \\
\text { rehearse till criterion is met. (This } \\
\text { step was not done in this study). } \\
\text { * Repeat the same steps with all } \\
\text { series of nonwords. }\end{array}$ & $\begin{array}{l}\text { Augmented feedback: } \\
\text { Provide KR feedback } \\
\text { (knowledge of results) on } \\
100 \% \text { of first trials during } \\
\text { blocked practice, but reduce } \\
\text { gradually. During repetition of } \\
\text { a series only provide feedback } \\
\text { if a nonword is consistently } \\
\text { produced incorrectly. } \\
\text { Delay KR feedback } 3 \text { to } 4 \\
\text { seconds after the response and } \\
\text { provide only if client did not } \\
\text { successfully self-correct. } \\
\text { Criteria for correct } \\
\text { production: } \\
\text { No groping, start-restart } \\
\text { behaviour, distortions, } \\
\text { substitutions, distorted } \\
\text { substitutions, additions, } \\
\text { omissions, or trans-positioning. } \\
\text { Syllable segregation and } \\
\text { prolonged duration are } \\
\text { acceptable and regarded as } \\
\text { compensatory strategies. }\end{array}$ \\
\hline
\end{tabular}

